\title{
Coordination Properties of GdDO3A-Based Model Compounds of Bioresponsive MRI Contrast Agents
}

\author{
Serhat Gündüz, ${ }^{\dagger}$ Sandip Vibhute, ${ }^{\dagger}$ Richard Botár, ${ }^{\dagger}$ Ferenc K. Kálmán, ${ }^{*}{ }^{\ddagger}$ Imre Tóth, ${ }^{\ddagger}$ Gyula Tircsó, ${ }^{\ddagger}$ \\ Martín Regueiro-Figueroa, ${ }^{\S}$ David Esteban-Gómez, ${ }^{\S \odot}$ Carlos Platas-Iglesias, ${ }^{\S}$ and Goran Angelovski*,†
}

${ }^{\dagger}$ MR Neuroimaging Agents, Max Planck Institute for Biological Cybernetics, D-72076 Tuebingen, Germany

${ }^{\ddagger}$ Department of Inorganic and Analytical Chemistry, Faculty of Science and Technology, University of Debrecen, Egyetem tér 1, H-4032 Debrecen, Hungary

${ }^{\S}$ Centro de Investigaciones Científicas Avanzadas (CICA) and Departamento de Química, Universidade da Coruña, Campus da Zapateira, Rúa da Fraga 10, 15008 A Coruña, Spain

\section{Supporting Information}

ABSTRACT: We report a detailed characterization of the thermodynamic stability and dissociation kinetics of $\mathrm{Gd}^{3+}$ complexes with DO3A derivatives containing a (methylethylcarbamoylmethylamino)acetic acid $\left(\mathbf{L}^{\mathbf{1}}\right)$, (methylpropylcarbamoylmethylamino)acetic acid $\left(\mathbf{L}^{2}\right), 2$-dimethylamino- $N$-ethylacetamide $\left(\mathbf{L}^{3}\right)$, or 2-dimethylamino- $N$-propylacetamide $\left(\mathrm{L}^{4}\right)$ group attached to the fourth nitrogen atom of the macrocyclic unit. These ligands are model systems of $\mathrm{Ca}^{2+}$ - and $\mathrm{Zn}^{2+}$-responsive contrast agents (CA) for application in magnetic resonance imaging (MRI). The results of the potentiometric studies $(I=0.15 \mathrm{M} \mathrm{NaCl})$ provide stability constants with $\log K_{\mathrm{GdL}}$ values in the range 13.9-14.8. The complex speciation in solution was found to be quite complicated due to the formation of protonated species at low $\mathrm{pH}$, hydroxido complexes at high $\mathrm{pH}$, and stable dinuclear complexes in the case of $\mathrm{L}^{\mathbf{1 , 2}}$. At neutral $\mathrm{pH}$ significant fractions of the complexes are protonated at the amine group of the amide side chain $\left(\log K_{\mathrm{GdL} \times \mathrm{H}}=7.2-8.1\right)$. These ligands form rather weak complexes with $\mathrm{Mg}^{2+}$ and Ca $\mathrm{Ca}^{2+}$ but very stable complexes with $\mathrm{Cu}^{2+}\left(\log K_{\mathrm{CuL}}=20.4-22.3\right)$ and $\mathrm{Zn}^{2+}\left(\log K_{\mathrm{ZnL}}=15.5-17.6\right)$. Structural studies using a combination of ${ }^{1} \mathrm{H} \mathrm{NMR}$ and luminescence spectroscopy show that the amide group of the ligand is coordinated to the metal ion at $\mathrm{pH} \sim 8.5$, while protonation of the amine group provokes the decoordination of the amide $\mathrm{O}$ atom and a concomitant increase in the hydration number and proton relaxivity. The dissociation of the complexes occurs mainly through a rather efficient proton-assisted pathway, which results in kinetic inertness comparable to that of nonmacrocyclic ligands such as DTPA rather than DOTA-like complexes.

\section{INTRODUCTION}

MRI contrast agents capable of following biological processes are receiving increased attention in molecular imaging, especially those that exist as complexes of paramagnetic lanthanide metal ions with cyclen-based macrocyclic ligands. ${ }^{1}$ These so-called bioresponsive or smart CAs (SCAs) change their properties due to perturbations occurring in their microenvironment that are triggered by the analyte or event of interest, such as a change in concentration of a target ion, or enzyme activity. ${ }^{2,3}$ For instance, SCAs that are suitable for $T_{1^{-}}$ weighted MRI undergo changes in their longitudinal relaxivity $r_{1}$ and consequently the $T_{1}$ relaxation times of solvent water molecules vary as a result of biological stimuli. This $r_{1}$ alteration is induced by changes in one or a combination of several parameters that affect $r_{1}$, such as the number of inner-sphere water molecules $(q)$, their exchange rate with bulk water $\left(k_{\mathrm{ex}}\right)$, or the rotational correlation time $\left(\tau_{\mathrm{r}}\right){ }^{1}$
Taking advantage of changes in the hydration number of the complexes, we have developed a considerable number of potential SCAs that were designed to respond to $\mathrm{pH}$, endogenous ions such as $\mathrm{Ca}^{2+}$ and $\mathrm{Zn}^{2+}$, or amino acid neurotransmitters. ${ }^{4-10}$ Moreover, these initial or structurally modified SCAs exhibited very advantageous properties in different buffered media, living brain slices, in vivo or also at a frequency suitable for ${ }^{19} \mathrm{~F}$ MRI. ${ }^{4,10-15}$

The responsive units of many of these SCAs consisted of a DO3A chelator for paramagnetic $\mathrm{Gd}^{3+}$, coupled via ethyl or propyl linkers and an amide bond to the desired recognition unit, e.g. EGTA, TACN, or crown ether derived chelators for $\mathrm{Ca}^{2+}, \mathrm{Zn}^{2+}$, or amino groups, respectively. Furthermore, our initial studies on the exact triggering mechanism with this

Received: February 21, 2018 
particular responsive unit revealed an intricate process that involves different interactions of two geometrical DO3A isomers with the same target analyte. Namely, the major isomer present in solution, which presents an SAP coordination environment, contains a carboxylate group of the EGTA moiety coordinated to $\mathrm{Gd}^{3+}$. Addition of $\mathrm{Ca}^{2+}$ causes the flipping of this carboxylate to bind $\mathrm{Ca}^{2+}$ and its decoordination from the paramagnetic metal center giving rise to a higher $q .{ }^{15}$ On the other hand, the minor TSAP isomer apparently does not undergo the Ca-induced $q$ alteration process - the carboxylate group does not initially coordinate to the paramagnetic metal center in the absence of $\mathrm{Ca}^{2+}$, and hence complexation with $\mathrm{Ca}^{2+}$ has no major influence on $q$ and consequently $r_{1}$.

Intrigued by the findings of these preliminary mechanistic studies, we programmed a more detailed coordination chemistry investigation of these chelating systems that provide SCAs. To this aim, we designed the four ligands $L^{1-4}$ that should mimic the behavior of the DO3A-derived responsive units of SCAs in the presence and absence of $\mathrm{Ca}^{2+}$ or $\mathrm{Zn}^{2+}$ (e.g., $\left.\mathrm{SCA}^{1,2}\right){ }^{6}$ without actually having $\mathrm{Ca}$ - or $\mathrm{Zn}$-binding units (Chart 1). Specifically, we anticipated that two ligands $\left(\mathbf{L}^{\mathbf{1 , 2}}\right)$

Chart 1. Structures of Paramagnetic Complexes $\mathrm{LnL}^{1-4}(\mathrm{Ln}=$ Gd, Eu, Yb) Investigated in This Work and Their Analogy to the Ca-Responsive Bis-Macrocyclic Contrast Agents SCA ${ }^{1,2} 6$<smiles>CN(CCN(CCNC(=O)[O-])CCN(CCN(CCN(CC(=O)[O-])CC(=O)[O-])CC(=O)[O-])CCN(CC(=O)[O-])CC(=O)[O-])CC(=O)[O-]</smiles><smiles>CN(C)CCN(CCNC(=O)CN(C)C)CCN(CCN(CC(=O)[O-])CC(=O)O)CCN(CC(=O)O)CC(=O)O</smiles>

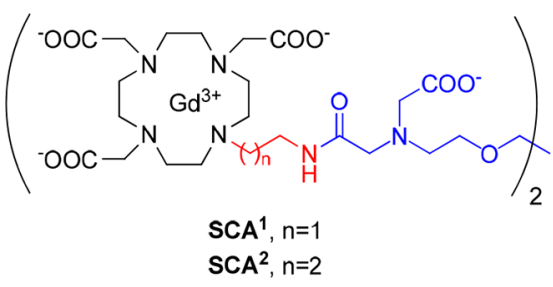

can mimic the coordination of the responsive unit with the paramagnetic metal center in the absence of the analyte by installing a carboxylate on the $\mathrm{N}$-methylene group of the side chain (i.e., $\mathbf{S C A}^{\mathbf{1 , 2}}$ in the absence of $\mathrm{Ca}^{2+}$ ). On the other hand, the absence of the carboxylate at the $N, N$-dimethyl group in the remaining two ligands $\mathbf{L}^{3,4}$ could serve as the model of coordination properties in the presence of the metal analyte (i.e., $\mathbf{S C A}^{\mathbf{1 , 2}}$ in the presence of $\mathrm{Ca}^{2+}$ ), as we anticipated that the missing carboxylate group coordinates to the added analyte and is not available to the DO3A-derived responsive unit. In addition, the influence of the distance of the 2-(methylamino)acetate group or $\mathrm{N}, \mathrm{N}$-dimethylamino group was investigated by preparing ligands with two different chain lengths between the DO3A unit and the amide bearing the aforementioned amine groups, specifically ethyl or propyl linkers for ligands $L^{1,3}$ and
$\mathbf{L}^{2,4}$, respectively. Following their successful synthesis, we prepared different paramagnetic metal complexes and investigated their coordination properties by means of NMR spectroscopy, steady-state and time-resolved luminescence spectroscopy, and DFT calculations, as well as the thermodynamic stability by $\mathrm{pH}$-potentiometry supplemented with ${ }^{1} \mathrm{H}$ relaxometry and the inertness of the $\mathrm{Gd}^{3+}$ complexes accessed by studying metal exchange reactions. In addition to the determination of the stability constants of the complexes with $\mathrm{Gd}^{3+}$ ions, we also investigated the stabilities of the complexes formed with divalent metal ions available in vivo $\left(\mathrm{Mg}^{2+}, \mathrm{Ca}^{2+}\right.$, $\mathrm{Zn}^{2+}$ and $\mathrm{Cu}^{2+}$ ).

\section{RESULTS AND DISCUSSION}

Ligand Synthesis. The ligands $\mathbf{L}^{1-4}$ were prepared in a straightforward fashion using previously reported bromides and commercially available amines as hydrochloride salts (Scheme $1)$. In the first step, the alkylation of sarcosine tert-butyl ester hydrochloride or dimethylamine hydrochloride with 1 and $2^{6}$ yielded $t \mathrm{Bu}$ ester protected compounds 3 and 4 or 5 and $\mathbf{6}$, respectively. The macrocycles 3-6 underwent acid hydrolysis of the $t \mathrm{Bu}$ esters with formic acid or $\mathrm{HCl}$ to afford $\mathrm{L}^{1-4}$.

Protonation Constants of the Model Ligands $L^{1-4}$. The protonation equilibria of ligands $\mathrm{H}_{4} \mathrm{~L}^{\mathbf{1 , 2}}$ and $\mathrm{H}_{3} \mathrm{~L}^{3,4}$ were studied by $\mathrm{pH}$-potentiometry. The protonation constants defined by eq 1 were evaluated from the corresponding $\mathrm{pH}-$ $V(\mathrm{~mL})$ titration curves. The results were compared with the protonation constants of ligands DO3A, DOTA, EAEA-DO3A, and EAPA-DO3A in Table 1 (see also Chart 2).

$$
K_{i}^{\mathrm{H}}=\frac{\left[\mathrm{H}_{i} \mathrm{~L}\right]}{\left[\mathrm{H}_{i-1} \mathrm{~L}\right]\left[\mathrm{H}^{+}\right]} \quad i=1-6
$$

Ligands $\mathbf{L}^{1-4}$ present three fairly basic sites with $\log K$ values in the range 7.4-9.6, in contrast to the protonation constants observed for DO3A and DOTA, ${ }^{16}$ which present only two protonation processes with $\log K>7$. In this regard, the protonation sequence of $\mathrm{L}^{1-4}$ resembles that of EAEA-DO3A, EAPA-DO3A, and DMAE-DO3A, ${ }^{17,18}$ which incorporate amine groups in one of the pendant arms connected by an ethyl or propyl linker. Thus, the two highest protonation constants of $\mathbf{L}^{1-4}$ can be assigned to the protonation of two trans nitrogen atoms of the macrocycle, which is typical of DOTA-like systems. ${ }^{19}$ The $\log K_{3}{ }^{\mathrm{H}}$ values in $\mathbf{L}^{\mathbf{1 - 4}}$ ligands belong to a basic amino $\mathrm{N}$ atom of the pendant arm.

The $\log K_{1}$ and $\log K_{2}$ values of $\mathbf{L}^{1}$ and $\mathbf{L}^{3}$ are very similar and somewhat lower than those of $\mathbf{L}^{2}$ and $\mathbf{L}^{4}$. This phenomenon can be attributed, at least in part, to the longer propyl linker connecting the nitrogen atom of the macrocycle and the amide group in $\mathbf{L}^{2}$ and $\mathbf{L}^{4}$, which likely results in a lower electron-withdrawing effect of the amide moiety. Even so, the $\log K_{1}$ values determined for $\mathbf{L}^{1-4}$ are considerably lower than the corresponding constants determined for the ligands shown in Chart 2. A possible explanation of this effect might be the different ionic strengths used to determine the two sets of data $\left(0.15 \mathrm{M} \mathrm{NaCl}\right.$ for $\mathbf{L}^{\mathbf{1 - 4}}$ and $0.1 \mathrm{M} \mathrm{KCl}$ for DO3A, DOTA, EAEA-DO3A, and EAPA-DO3A), as the formation of a weak $\mathrm{Na}^{+}$complex competing with the first protonation step can result in lower protonation constants. ${ }^{20,21}$ Thus, we have also determined the protonation constants of DO3A using a $0.15 \mathrm{M}$ $\mathrm{NaCl}$ ionic strength (Table 1). Indeed, the first protonation constant determined for $\mathrm{DO} 3 \mathrm{~A}$ in $0.15 \mathrm{M} \mathrm{NaCl}$ is $1.3 \log \mathrm{K}$ units lower than that obtained in $0.1 \mathrm{M} \mathrm{KCl}$, which shows that 


\section{Scheme 1. Synthesis of ligands $\mathrm{L}^{1-4 a}$}

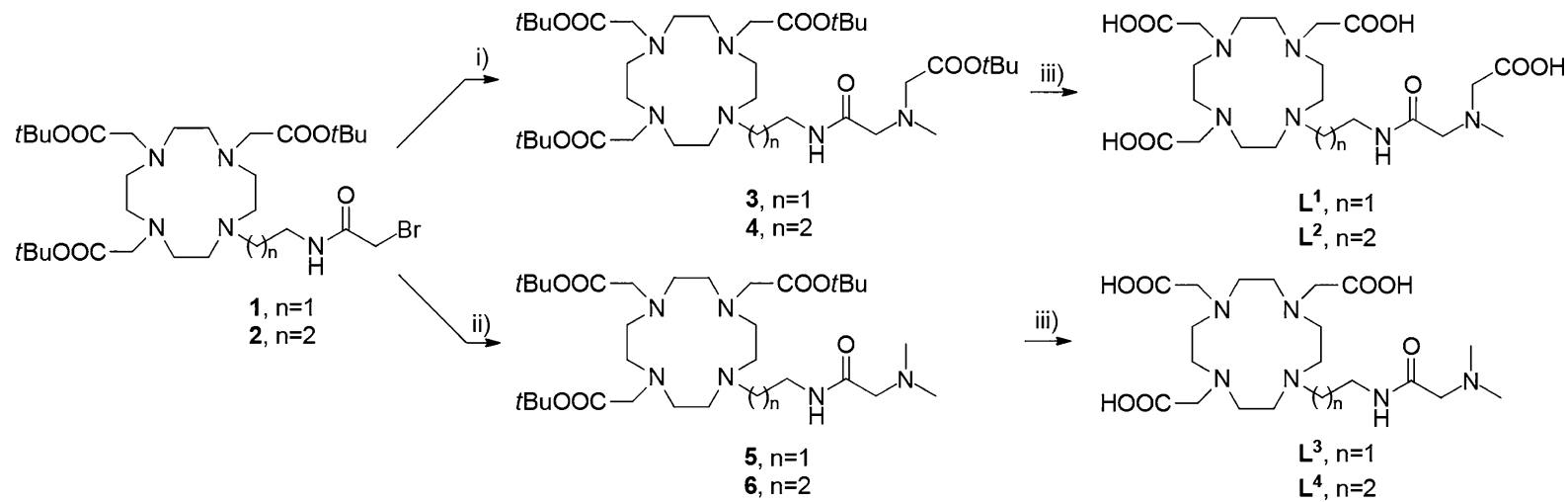

${ }^{a}$ Reaction conditions: (i) sarcosine tert-butyl ester hydrochloride, $\mathrm{K}_{2} \mathrm{CO}_{3}, \mathrm{CH}_{3} \mathrm{CN}, 70{ }^{\circ} \mathrm{C}, 16 \mathrm{~h}$; (ii) dimethylamine hydrochloride, $\mathrm{K}_{2} \mathrm{CO}_{3}, \mathrm{CH}_{3} \mathrm{CN}_{\text {, }}$ $70{ }^{\circ} \mathrm{C}, 16 \mathrm{~h}$; (iii) $\mathrm{HCOOH}, 60{ }^{\circ} \mathrm{C}, 16 \mathrm{~h}$.

$\mathrm{Na}^{+}$complex formation is partially responsible for the low protonation constants determined for $\mathrm{L}^{1-4}$. The slightly higher $\log K_{1}{ }^{\mathrm{H}}$ values of $\mathrm{L}^{2,4}$ in comparison to those of $\mathbf{L}^{1,3}$ might also be explained by the higher stability of the $\mathrm{Na}^{+}$complexes formed by the latter ligands. An additional factor that may be responsible for the $\log K_{1}$ values of $\mathrm{L}^{1-4}$ may be related to the formation of intramolecular hydrogen bonds involving the amide side chain and the nitrogen atoms of the cyclen unit.

The fourth and fifth protonation processes of $\mathrm{L}^{1-4}$ occur on the acetate moieties appended on the macrocycles, while the sixth protonation likely corresponds either to the protonation of the 2-(methylamino)acetate moiety (for $\mathbf{L}^{1}$ and $\mathbf{L}^{2}$ ) or to a third nitrogen atom of the macrocyclic ring $\left(\mathbf{L}^{3}\right)$.

It is well-known that the stability constants of lanthanide complexes formed with polyamino polycarboxylates or polyphosphonates are directly proportional to the total basicity of the ligands, if all the donor atoms are involved both in protonation and complexation. ${ }^{1}$ Thus, the $\sum_{i=1}^{6} \log K_{i}{ }^{\mathrm{H}}$ values obtained for $\mathbf{L}^{\mathbf{1 - 4}}$ (Table 1) are not adequate for comparison with ligands such as DO3A and DOTA, since the $\log K_{3}{ }^{\mathrm{H}}$ value of $\mathbf{L}^{1-4}$ (and the $\log K_{6}{ }^{\mathrm{H}}$ values of $\mathbf{L}^{1}$ and $\mathbf{L}^{2}$ ) corresponds to the protonation of basic sites that are not involved in the coordination to the metal ion. For that reason, we have calculated the $\sum_{i=1}^{4} \log K_{i}^{\mathrm{H}^{*}}$ values by considering only the protonation constants characterizing the basicity of the DO3A metal binding unit (Table 1) and omitting the $\log K_{3}$ and $\log$ $K_{6}$ values for the calculation of $\sum_{i=1}^{4} \log K_{i}^{\mathrm{H}^{*}}$. Consequently, the $\sum_{i=1}^{4} \log K_{i}^{\mathrm{H}^{*}}$ values obtained for $\mathbf{L}^{1-4}$ are clearly lower than those of DO3A and DOTA, anticipating a lower stability of the complexes reported here.

The complexation equilibria of $\mathrm{L}^{1-4}$ with $\mathrm{Mg}^{2+}, \mathrm{Ca}^{2+}, \mathrm{Zn}^{2+}$, $\mathrm{Cu}^{2+}$ and $\mathrm{Gd}^{3+}$ ions were studied in detail by means of $\mathrm{pH}-$ potentiometric, spectrophotometric, and/or ${ }^{1} \mathrm{H}$-relaxometric methods. The constants characterizing the formation of metal chelates can be expressed with eqs 2 and 3, with the former being the general equation for defining the ligand protonation constants and the second giving cumulative stabilities of the complexes.

$$
\begin{aligned}
& p \mathrm{M}^{n+}+q \mathrm{H}^{+}+r \mathrm{~L}^{m-} \leftrightarrows \mathrm{M}_{p} \mathrm{H}_{q} \mathrm{~L}_{r}^{p n+q-r m} \\
& \beta_{p q r}=\frac{\left[\mathrm{M}_{p} \mathrm{H}_{q} \mathrm{~L}_{r}^{p n+q-r m}\right]}{\left[\mathrm{M}^{n+}\right]^{p}\left[\mathrm{H}^{+}\right]^{q}\left[\mathrm{~L}^{m-}\right]^{r}}
\end{aligned}
$$

The stability constants ( $\log K$ values) shown in Table 1 were calculated from $\log \beta$ values assuming that the $\log K_{\mathrm{ML}}$ values are equal to $\log \beta_{\mathrm{ML}}$ values, whereas the $\log K_{\mathrm{MHL}}$ and $\log$ $K_{\mathrm{MLH}-1}$ values are defined as protonation constants. The $K_{\mathrm{ML} \times \mathrm{M}}$ constants correspond to the formation of $\mathrm{M}_{2} \mathrm{~L}$ from $\mathrm{ML}$ and $\mathrm{M}$ (the corresponding equations are shown in the Supporting Information). The stability constants of the $\mathrm{Mg}^{2+}, \mathrm{Ca}^{2+}$ and $\mathrm{Zn}^{2+}$ complexes could be determined by a direct $\mathrm{pH}$ potentiometric method. Due to the high stability constants of the $\mathrm{CuL}^{1-4}$ complexes (found to form quantitatively already below $\mathrm{pH}<1.7$ ), $\mathrm{pH}$-potentiometry was supplemented by UVvis spectrophotometry. Finally, the formation of the $\mathrm{Gd}^{3+}$ complexes (occurring in the $\mathrm{pH}$ range $3-5$ ) is slow. For this reason, the stability constants of the $\mathrm{GdL}^{1-4}$ complexes were determined using the out-of-cell (batch) method, equilibrating the samples at $25{ }^{\circ} \mathrm{C}$ over a period of several weeks. ${ }^{22}$ The equilibrium constants characterizing the deprotonation that occurs at basic $\mathrm{pH}$ (deprotonation of amine groups, as well as the formation of ternary hydroxido complexes) were determined from the data obtained via direct $\mathrm{pH}$-potentiometric titrations performed on the preformed complexes.

Simultaneous fitting of the titration curves obtained at different metal to ligand ratios $(1: 1,2: 1)$ indicated the formation of mononuclear $([\mathrm{M}(\mathrm{L})])$ and monoprotonated $([\mathrm{M}(\mathrm{HL})])$ forms of the $\mathrm{Mg}^{2+}$ and $\mathrm{Ca}^{2+}$ complexes of ligands $\mathrm{L}^{1-4}$ in all cases. Furthermore, the fitting of the titration data also confirmed the formation of binuclear complexes of $\mathbf{L}^{1}$ and $\mathrm{L}^{2}$ with $\mathrm{Mg}^{2+}, \mathrm{Cu}^{2+}$, and $\mathrm{Zn}^{2+}$ ions $\left(\left[\mathrm{M}_{2}(\mathrm{~L})\right]\right)$. Di- and triprotonated species were also assumed for fitting the titration data obtained for the $\mathbf{L}^{\mathbf{1 , 2}}$ systems with $\mathrm{Ca}^{2+}$ and $\mathrm{Cu}^{2+}$ or $\mathrm{Zn}^{2+}$, respectively. The lack of binuclear and diprotonated complexes of $\mathrm{L}^{3,4}$ with the majority of metal ions studied (except $\mathrm{Cu}^{2+}$ ) can be attributed to the absence of the carboxylate group on the amide pendant arm.

The values of the stability constants for the $\mathrm{L}^{1-4}$ complexes with $\mathrm{Mg}^{2+}$ and $\mathrm{Ca}^{2+}$ ions were found to be lower than those of the DO3A and DOTA complexes (Table 1). This phenomenon might be explained partially by the lower basicity of the donor atoms involved in the metal binding and partially by the more flexible structure of their coordination cavity. Additionally, the replacement of an acetamide arm with a propionamide unit can also negatively affect the stability constants. ${ }^{17}$ However, a comparison between the third protonation of the $\mathrm{L}^{1-4}$ ligands and the first protonation of the $\mathrm{Mg}^{2+}$ and $\mathrm{Ca}^{2+}$ complexes (characterizing the protonation of the amine group of the 
Table 1. Protonation Constants of the Ligands $\mathrm{L}^{1-4}$ and Stability and Protonation Constants of the Complexes Formed with $\mathrm{L}^{1-4}$ and Selected DOTA-Based Ligands ${ }^{a}$

\begin{tabular}{|c|c|c|c|c|c|c|c|c|c|}
\hline & \multicolumn{9}{|c|}{ ligand } \\
\hline & $\mathrm{L}^{1}$ & $\mathrm{~L}^{2}$ & $\mathrm{~L}^{3}$ & $\mathrm{~L}^{4}$ & $\mathrm{DO} 3 \mathrm{~A}^{b-d}$ & DOTA $^{b, c}$ & $\begin{array}{l}\text { EAEA- } \\
\text { DO3A }^{e}\end{array}$ & $\begin{array}{l}\text { EAPA- } \\
\text { DO3A }^{e}\end{array}$ & $\begin{array}{l}\text { DMAE- } \\
\text { DO3A }^{f}\end{array}$ \\
\hline $\log K_{1}^{\mathrm{H}}$ & $9.15(2)$ & $9.57(1)$ & $9.23(1)$ & $9.59(4)$ & 11.99 & 11.41 & 11.77 & 11.00 & 11.92 \\
\hline $\log K_{2}^{\mathrm{H}}$ & $9.21(1)$ & $9.54(1)$ & $9.03(3)$ & $9.37(2)$ & 9.51 & 9.83 & 9.98 & 9.52 & 9.84 \\
\hline $\log K_{3}{ }^{\mathrm{H}}$ & $7.54(2)$ & $7.11(1)$ & $8.08(2)$ & $7.45(4)$ & 4.30 & 4.38 & 9.33 & 8.98 & 8.72 \\
\hline $\log K_{4}^{\mathrm{H}}$ & $4.60(1)$ & $4.32(1)$ & $4.29(3)$ & $3.81(5)$ & 3.63 & 4.63 & 4.01 & 4.59 & 4.25 \\
\hline $\log K_{5}{ }^{\mathrm{H}}$ & $2.84(1)$ & $3.37(1)$ & $2.74(2)$ & $2.64(1)$ & 1.84 & 1.92 & 1.99 & 3.12 & 1.93 \\
\hline $\log K_{6}^{\mathrm{H}}$ & $1.99(7)$ & $2.62(1)$ & $1.45(2)$ & & & 1.58 & 1.53 & 1.88 & \\
\hline $\log \beta_{i}^{\mathrm{H}}$ & $35.33(i=6)$ & $36.53(i=6)$ & $35.54(i=6)$ & $32.86(i=5)$ & $31.26(i=5)$ & $33.75(i=6)$ & $38.61(i=6)$ & $39.09(i=6)$ & $36.83(i=5)$ \\
\hline$\sum_{i=1}^{4} \log K_{i}^{\mathrm{H}^{*}}$ & 25.80 & 26.80 & 25.29 & 25.41 & 29.43 & 30.25 & 27.75 & 27.23 & 28.23 \\
\hline $\log K_{\mathrm{MgL}}$ & $7.09(4)$ & $7.69(3)$ & $6.54(4)$ & $7.23(5)$ & 11.64 & 11.49 & & & \\
\hline $\log K_{\mathrm{MgL} \times \mathrm{H}}$ & $7.68(3)$ & $7.54(2)$ & 7.99 & $7.92(6)$ & & & & & \\
\hline $\log K_{\mathrm{MgL} \times \mathrm{Mg}}$ & $2.68(8)$ & $2.87(5)$ & & & & & & & \\
\hline $\log K_{\mathrm{CaL}}$ & $10.22(6)$ & $9.85(3)$ & $9.02(7)$ & $10.13(7)$ & 12.57 & 16.11 & & & 12.68 \\
\hline $\log K_{\mathrm{CaL} \times \mathrm{H}}$ & $6.90(4)$ & $7.06(2)$ & $7.97(4)$ & $7.53(4)$ & 4.60 & 3.67 & & & 8.72 \\
\hline $\log K_{\mathrm{CaHL} \times \mathrm{H}}$ & $5.68(9)$ & $5.64(7)$ & & & & & & & 5.20 \\
\hline $\log K_{\mathrm{ZnL}}$ & $17.32(9)$ & $17.64(13)$ & $15.54(8)$ & $16.84(9)$ & 21.57 & 20.21 & & & 20.09 \\
\hline $\log K_{\mathrm{ZnL \times H}}$ & $7.34(4)$ & $7.01(4)$ & $7.78(4)$ & $7.89(5)$ & 3.47 & 4.12 & & & 8.75 \\
\hline $\log K_{\mathrm{ZnHL} \times \mathrm{H}}$ & $4.05(4)$ & $3.88(7)$ & $4.18(5)$ & $3.84(4)$ & 2.07 & 3.49 & & & 3.92 \\
\hline $\log K_{\mathrm{ZnH} 2 \mathrm{~L} \times \mathrm{H}}$ & $3.17(2)$ & $3.37(3)$ & $3.81(2)$ & $2.95(2)$ & & 2.56 & & & 2.63 \\
\hline $\log K_{\mathrm{ZnH} 3 \mathrm{~L} \times \mathrm{H}}$ & $2.46(4)$ & $3.45(6)$ & & & & & & & \\
\hline $\log K_{\mathrm{ZnL} \times \mathrm{H}-1}$ & $11.97(9)$ & $12.69(19)$ & & & & & & & \\
\hline $\log K_{\mathrm{ZnL} \times \mathrm{Zn}}$ & $5.12(9)$ & $5.71(10)$ & & & & & & & \\
\hline $\log K_{\mathrm{Zn} 2 \mathrm{~L} \times \mathrm{H}-1}$ & $8.20(11)$ & $7.88(14)$ & & & & & & & \\
\hline $\log K_{\mathrm{Zn} 2 \mathrm{~L} \times \mathrm{H}-2}$ & $9.61(11)$ & $9.29(13)$ & & & & & & & \\
\hline $\log K_{\mathrm{Zn} 2 \mathrm{~L} \times \mathrm{H}-3}$ & $12.16(9)$ & $11.85(10)$ & & & & & & & \\
\hline $\log K_{\mathrm{CuL}}$ & $21.38(7)$ & $22.33(4)$ & $20.38(3)$ & $20.54(8)$ & 25.89 & 24.83 & & & 24.80 \\
\hline $\log K_{\mathrm{CuL} \times \mathrm{H}}$ & $7.01(5)$ & $7.04(2)$ & $7.72(2)$ & $7.67(4)$ & 3.65 & 4.12 & & & 8.69 \\
\hline $\log K_{\mathrm{CuHL} \times \mathrm{H}}$ & $4.16(6)$ & $3.80(2)$ & $4.11(2)$ & $3.59(2)$ & 1.81 & 3.57 & & & 3.79 \\
\hline $\log K_{\mathrm{CuH} 2 \mathrm{~L} \times \mathrm{H}}$ & $2.82(6)$ & $3.03(8)$ & $2.88(2)$ & $1.59(2)$ & & 0.87 & & & 1.47 \\
\hline $\log K_{\mathrm{CuH} 3 \mathrm{~L} \times \mathrm{H}}$ & & & $1.76(3)$ & & & & & & \\
\hline $\log K_{\mathrm{CuL} \times \mathrm{H}-1}$ & & $11.75(6)$ & & & & & & & \\
\hline $\log K_{\mathrm{CuL} \times \mathrm{Cu}}$ & $8.37(8)$ & $7.33(5)$ & & & & & & & \\
\hline $\log K_{\mathrm{Cu} 2 \mathrm{~L} \times \mathrm{H}}$ & $3.87(7)$ & $4.01(1)$ & & & & & & & \\
\hline $\log K_{\mathrm{Cu} 2 \mathrm{~L} \times \mathrm{H}-1}$ & $5.71(10)$ & $7.48(5)$ & & & & & & & \\
\hline $\log K_{\mathrm{Cu} 2 \mathrm{~L} \times \mathrm{H}-2}$ & $9.38(11)$ & $9.87(6)$ & & & & & & & \\
\hline $\log K_{\mathrm{Cu} 2 \mathrm{~L} \times \mathrm{H}-3}$ & $12.02(13)$ & $12.80(10)$ & & & & & & & \\
\hline $\log K_{\mathrm{GdL}}$ & $14.80(6)$ & $14.40(8)$ & $14.59(5)$ & $13.89(4)$ & $\begin{array}{l}21.56 \\
\quad\left(19.06(4)^{g}\right)\end{array}$ & 24.70 & 22.25 & 20.22 & 20.56 \\
\hline $\log K_{\mathrm{GdL} \times \mathrm{H}}$ & $7.15(8)$ & $7.37(8)$ & $7.66(6)$ & $8.09(9)$ & $h$ & & 9.24 & 8.40 & 7.98 \\
\hline $\log K_{\mathrm{GdLH}-1}$ & $9.92(8)$ & $11.77(8)$ & $9.09(6)$ & $11.64(5)$ & $i$ & & $h$ & & $h$ \\
\hline pGd & 12.02 & 11.15 & 11.77 & 11.17 & $15.85\left(16.37^{g}\right)$ & 19.21 & 14.52 & 14.93 & 14.89 \\
\hline
\end{tabular}

${ }^{a}$ Conditions: $25{ }^{\circ} \mathrm{C}, I=0.15 \mathrm{M} \mathrm{NaCl}$. Standard deviations are given in parentheses. ${ }^{b}$ Data corresponding to DO3A, DOTA, EAEA-DO3A, EAPADO3A, and DMAE-DO3A ligands were obtained from ref 16 with the use of $0.10 \mathrm{M} \mathrm{KCl} .{ }^{c}$ Data from ref $16 .{ }^{d}$ For the sake of better data comparison, the protonation constants of DO3A were also determined with the use of $I=0.15 \mathrm{M} \mathrm{NaCl}$ ionic strength, resulting in the following values: log $K_{1}^{\mathrm{H}}=$ 10.71(2), $\log K_{2}^{\mathrm{H}}=9.49(4), \log K_{3}{ }^{\mathrm{H}}=4.17(6), \log K_{4}^{\mathrm{H}}=3.55(5)$, and $\log K_{5}^{\mathrm{H}}=1.75(8) ;{ }^{e}$ Reference $17 .{ }^{f}$ Reference $18 .{ }^{g}$ Stability and pGd values were obtained with the use of $I=0.15 \mathrm{M} \mathrm{NaCl}$ ionic strength. This work. ${ }^{h}$ Not detected. ${ }^{i}$ Not studied.

amide pendant arm) indicates that the amine nitrogen of the pendant arms is not involved in coordination to the metal ion in the mononuclear species, since the protonation constants of the amine nitrogen atoms in the complexes are comparable to those found for the free ligands.

The stability constants of the dinuclear complexes (log $K_{\mathrm{MgLxMg}}$ ) of $\mathbf{M g}_{2} \mathbf{L}^{1}$ and $\mathbf{M g}_{2} \mathbf{L}^{2}$ are quite similar to that of the $[\mathrm{Mg}(\mathrm{IDA})]$ complex $(\log K=2.94){ }^{23}$ suggesting that the second $\mathrm{Mg}^{2+}$ ion binds weakly to the 2-(methylamino)acetate group. Albeit a bit surprising, the formation of a dinuclear complex for $\mathrm{Mg}^{2+}$ and not for $\mathrm{Ca}^{2+}$ may be explained easily.
Indeed, the analysis of the stability data for IDA complexes indicates the formation of a more stable complex with $\mathrm{Mg}^{2+}$ in comparison to $\mathrm{Ca}^{2+}\left(\log K_{[\mathrm{Mg}(\mathrm{IDA})]}=2.94\right.$; lo $\mathrm{g} K_{[\mathrm{Ca}(\mathrm{IDA})]}=$ $2.59) .^{23}$ Due to the presence of an amide instead of a carboxylate group in the IDA-like binding units of $\mathbf{L}^{1}$ and $\mathbf{L}^{2}$, the stability constants of the complexes formed with this fragment (i.e., stability of the dinuclear complex) are expected to be lower. Thus, in the case of $\mathrm{Ca}^{2+}$, the formation of dinuclear complexes likely becomes undetectable under the experimental conditions applied in the current study. 
Chart 2. Ligands Reported Previously in the Literature That Are Discussed in This Work<smiles>O=C(O)CN1CCNCCN(CC(=O)O)CCN(CC(=O)O)CC1</smiles>

DO3A<smiles>CC(C)CN1CCN(CC(=O)O)CCN(CC(=O)O)CCN(CC(=O)O)CC1C(=O)O</smiles>

EAEA-DO3A $(n=1)$ EAPA-DO3A $(n=2)$<smiles>O=C(O)CN1CCN(CC(=O)O)CCN(CC(=O)O)CCN(CC(=O)O)CC1</smiles>

DOTA

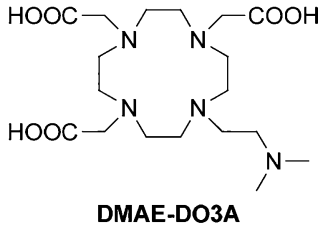

The equilibrium models of $\mathrm{ZnL}^{1,2}$ and $\mathrm{CuL}^{1,2}$ are more complex than those of $\mathrm{ZnL}^{3,4}$ and $\mathrm{CuL}^{3,4}$, which is related to the absence of the terminal carboxylic groups in the pendant arms of $\mathbf{L}^{3,4}$, inhibiting the formation of stable binuclear complexes. The stability constants of the mononuclear $\mathrm{Zn}^{2+}$ and $\mathrm{Cu}^{2+}$ complexes are also lower than those of the corresponding DO3A and DOTA complexes, which is not surprising given the lower basicity of the DO3A units of $\mathrm{L}^{\mathbf{1 - 4}}$. Representative speciation diagrams for the $\mathrm{CuL}^{2}$ and $\mathrm{CuL}^{4}$ systems are shown in Figure 1 (see also Figures S1-S6 in the Supporting Information).

The stability data indicate that the ligands with an ethylene linker between the amide group and the DO3A moiety $\left(\mathbf{L}^{1}\right.$ and $\mathbf{L}^{3}$ ) form $\mathrm{Cu}^{2+}$ and $\mathrm{Zn}^{2+}$ complexes of lower thermodynamic stability in comparison to those of $\mathbf{L}^{2}$ and $\mathbf{L}^{4}$, which contain a propylene linker. The reason for this may be the protonation of the amine nitrogen of the pendant arm accross a broad $\mathrm{pH}$ range (Figure 1), which causes electrostatic repulsion between the metal ion and the protonated $\mathrm{N}$ atom. This unfavorable electrostatic interaction would be more important for complexes having the shorter spacer. The similarity of the values of the first protonation constant obtained for the $\mathrm{Zn}^{2+}$ and $\mathrm{Cu}^{2+}$ complexes to the $\log K_{3}$ values of the ligands suggests that the amide pendant arms do not play an important role in complex formation. The additional protonation steps are related to the carboxylate moieties.

A similar trend for the formation of dinuclear complexes of $\mathrm{Mg}^{2+}$ and $\mathrm{Ca}^{2+}$ ions with the $\mathrm{L}^{\mathbf{1 , 2}}$ systems (see above) can be observed also with $\mathrm{Zn}^{2+}$ and $\mathrm{Cu}^{2+}$ ions. The stability constants of $[\mathrm{Zn}(\mathrm{IDA})]$ and $[\mathrm{Cu}(\mathrm{IDA})]$ are $\log K_{[\mathrm{Zn}(\mathrm{IDA})]}=7.03$ and $\log$ $K_{[\mathrm{Cu}(\mathrm{IDA})]}=10.6$, respectively, ${ }^{23}$ which are higher than those of the dinuclear complexes formed with $\mathbf{L}^{1}$ and $\mathbf{L}^{2}$ (Table 1). The drop in the stability constant of the dinuclear complexes may again be accounted for by the replacement of an acetate group with an amide moiety in the IDA-like binding unit, providing lower basicity and resulting in the formation of weaker complexes.

Several base consumption processes were observed in the titrations of $\mathbf{Z n}_{2} \mathbf{L}^{\mathbf{1 , 2}}$ and $\mathrm{Cu}_{2} \mathbf{L}^{\mathbf{1 , 2}}$ complexes above $\mathrm{pH}$ 5. By comparing the protonation constants of these processes (and the UV-vis spectra of the $\mathrm{Cu}^{2+}$ complexes, Figures S7-S14 in the Supporting Information), one can assume that the first two constants (which differ quite notably between $\mathbf{L}^{\mathbf{1}}$ and $\mathbf{L}^{2}$ ) belong to the deprotonation of the water molecules coordinated to the metal ions in the complexes. However, the deprotonations occurring near $\mathrm{pH} 12$ can be assigned to the dissociation of the amide proton, as absorption bands shift to lower wavelengths in both systems (Figures S9 and S11 in the Supporting Information). This suggests that the amide protons coordinate to the metal ion through the nitrogen atom upon deprotonation. $^{24}$

As previously mentioned, the complexation equilibria of the $\mathrm{GdL}^{1-4}$ complexes could not be followed by direct $\mathrm{pH}$ potentiometric titrations owing to slow complex formation. ${ }^{18,25-27}$ Thus, the stability and protonation constants of $\mathbf{G d L}^{1-4}$ were investigated by $T_{1}$ relaxometry (batch method) supplemented by $\mathrm{pH}$-potentiometric data obtained via direct titrations of the preformed complexes with a $\mathrm{HCl}$ solution (in the $\mathrm{pH}$ range of $11.85-5.6)$. Simultaneous fitting of the $\mathrm{pH}$ potentiometric and relaxometric data obtained for the $\mathbf{G d L}^{1-4}$ complexes indicated the formation of mononuclear species, as well as their monoprotonated $([\mathrm{Gd}(\mathrm{HL})])$ and ternary hydroxo $([\mathrm{Gd}(\mathrm{L})(\mathrm{OH})])$ complexes (Figure 2). As observed for the complexes of all other investigated metal ions, the stability constants of the $\mathrm{GdL}^{\mathbf{1 - 4}}$ complexes were lower than those for the corresponding $[\mathrm{Gd}(\mathrm{DO} 3 \mathrm{~A})]$ and $[\mathrm{Gd}(\mathrm{DOTA})]^{-}$ complexes. One of the reasons for this behavior could be the
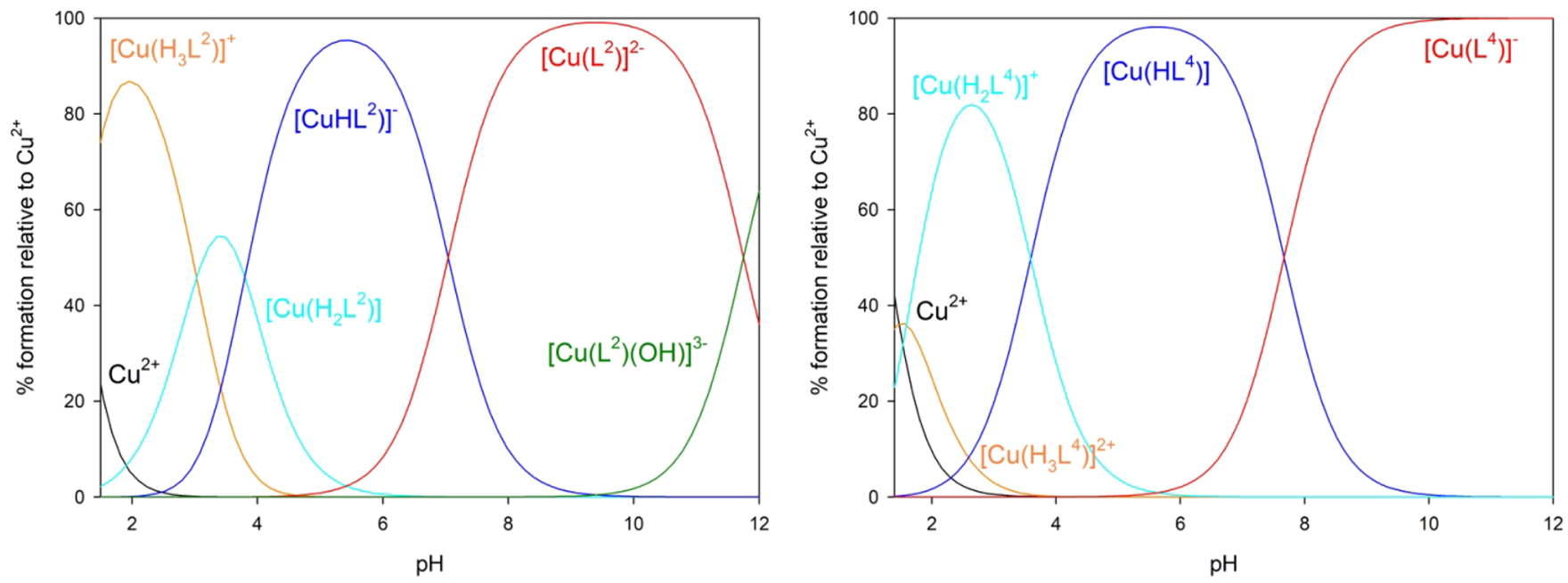

Figure 1. Species distribution of the $\mathrm{Cu}^{2+}: \mathrm{L}^{2}$ and $\mathrm{Cu}^{2+}: \mathrm{L}^{4}$ systems. Conditions: $1: 1 \mathrm{M}: \mathrm{L},\left[\mathrm{Cu}^{2+}\right]=1 \mathrm{mM}, I=0.15 \mathrm{M} \mathrm{NaCl}, 25^{\circ} \mathrm{C}$. 

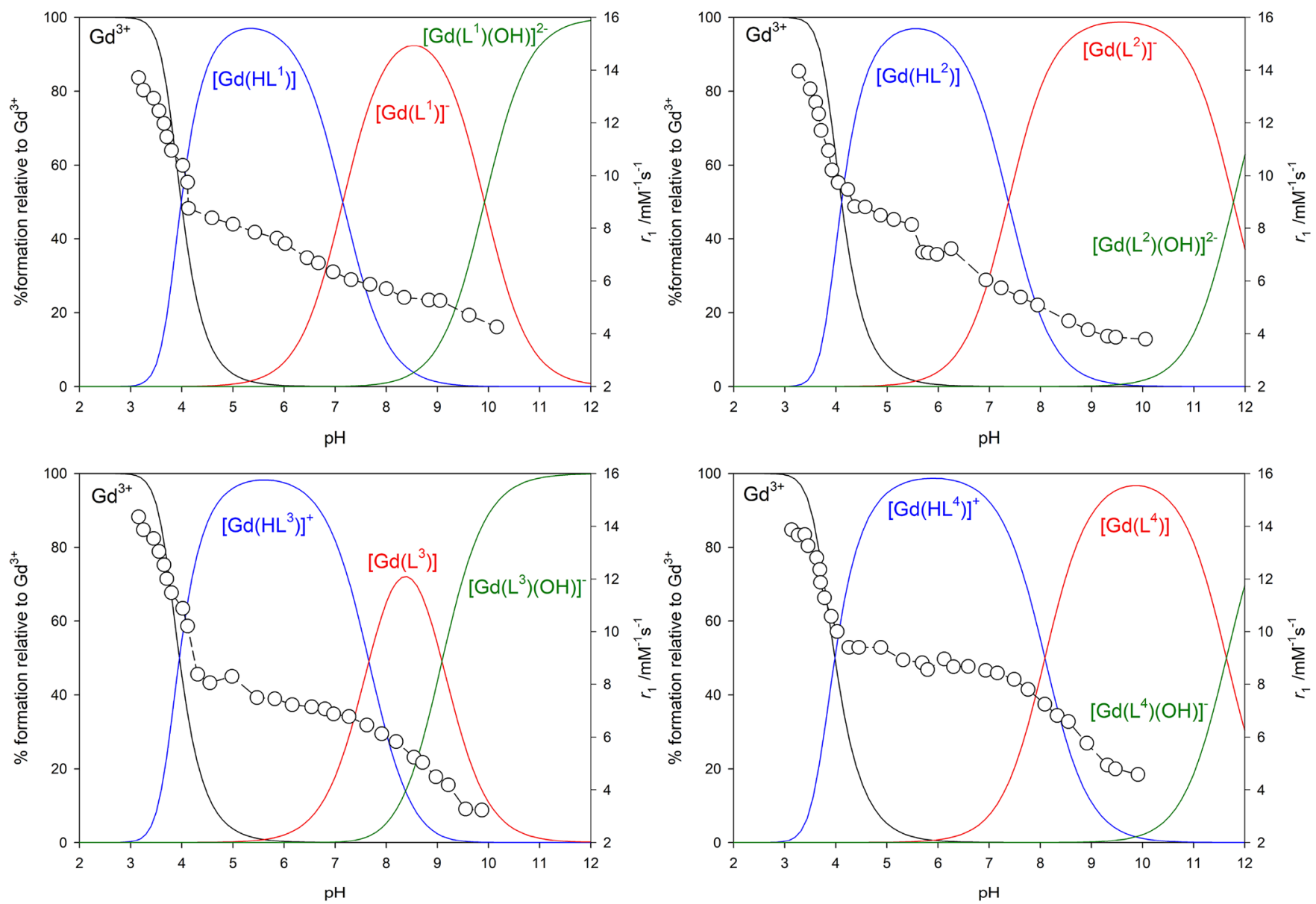

Figure 2. Species distribution of the $\mathrm{Gd}^{3+}: \mathbf{L}$ systems and their relaxometric profiles recorded at $20 \mathrm{MHz}(0.5 \mathrm{~T})$ at variable $\mathrm{pH}$ (circles). Conditions: $1: 1 \mathrm{Gd}: \mathrm{L},\left[\mathrm{Gd}^{3+}\right]=1 \mathrm{mM}, I=0.15 \mathrm{M} \mathrm{NaCl}, 25^{\circ} \mathrm{C}$.

use of $I=0.15 \mathrm{M} \mathrm{NaCl}$ ionic strength for stability constant determinations, which better resembles in vivo conditions. However, owing to complex formation in the presence of $\mathrm{Na}^{+}$ ions, the protonation equilibria occurring at high $\mathrm{pH}$ are shifted to lower $\mathrm{pH}$ and thus the ligands appear to possess lower basicity. On the other hand, the stability constants are also known to decrease when the methyl carboxylate (or acetamide) group is replaced by an ethyl or propyl carboxylate (or amide) moiety. ${ }^{17,27,28}$ The small and almost negligible differences between the protonation constant of the exocyclic amine group in the presence and absence of the $\mathrm{Gd}^{3+}$ ion indicate that the amine nitrogen atom is not involved in coordination to the metal ion.

The species distribution diagrams calculated for the $\mathbf{G d L}^{1-4}$ complexes indicate that dissociation of the complexes takes place below $\mathrm{pH} \sim 6$. At this $\mathrm{pH}$, the main species present in solution corresponds to the protonated complex, which is also the main species at physiological $\mathrm{pH}$. In the $\mathrm{pH}$ range ca. 8-11, the main species in solution corresponds to the nonprotonated complex for $\mathbf{G d L}^{2,4}$, while the hydroxo complexes predominate at rather high $\mathrm{pH}(>11)$. For $\mathrm{GdL}^{1,3}$ the formation of hydroxido species starts at lower $\mathrm{pH}$.

Structural and Proton Relaxometric Studies. ${ }^{1} \mathrm{H}$ relaxometric studies performed as a function of $\mathrm{pH}$ provide additional insight into the structure of the complexes in solution $\left(20 \mathrm{MHz}, 25{ }^{\circ} \mathrm{C}\right)$. The relaxivities of the four complexes increase gradually below $\mathrm{pH} \mathrm{10,} \mathrm{in} \mathrm{line} \mathrm{with} \mathrm{the}$ species distribution diagrams obtained from the stability constants reported in Table 1 . The low relaxivities observed at high $\mathrm{pH}$ are related to the formation of hydroxido complexes, as observed previously for other $\mathrm{Gd}^{3+}$ complexes. ${ }^{29}$ The complex species distribution patterns of $\mathbf{G d L}^{\mathbf{1 , 3}}$ make it difficult to estimate the relaxivities of the nonprotonated forms, while the $\left[\mathrm{Gd}\left(\mathbf{L}^{2}\right)\right]^{-}$and $\left[\mathrm{Gd}\left(\mathbf{L}^{4}\right)\right]$ species largely predominate at $\mathrm{pH} \sim 10$. The relaxivities observed at this $\mathrm{pH}$ (3.8 and 4.6 $\mathrm{mM}^{-1} \mathrm{~s}^{-1}$ at $20 \mathrm{MHz}$ and $25{ }^{\circ} \mathrm{C}$ ) are typical of small $\mathrm{Gd}^{3+}$ chelates containing one coordinated water molecule (or its corresponding hydroxide anion). These results suggest that the amide group on the pendant arm is coordinated to the $\mathrm{Gd}^{3+}$ ion, which is in line with our previous observations. ${ }^{15}$ The protonated complexes dominate the speciation in solution at $\mathrm{pH} \sim 6$ for all complexes. The corresponding relaxivities fall within the range $7.0-8.5 \mathrm{mM}^{-1} \mathrm{~s}^{-1}$, which are in line with the presence of two water molecules coordinated to the metal ion. $^{30}$

The longitudinal relaxivities of $\mathbf{G d L}^{1-4}$ were also determined at high magnetic field $(300 \mathrm{MHz} / 7 \mathrm{~T})$, thus allowing for better comparison with values obtained on previously studied SCAs sensitive to $\mathrm{Ca}^{2+}{ }^{4}$ A series of buffered $\mathrm{GdL}^{1-4}$ solutions in water ( $\mathrm{pH} \mathrm{7.4)} \mathrm{at} \mathrm{concentrations} \mathrm{ranging} \mathrm{from} 3.0$ to $5.0 \mathrm{mM}$ were prepared, and their relaxation times were measured (Figure 3).

The calculated $r_{1}$ values indicated quite different behavior of the complexes appended with the ethyl $\left(\mathbf{G d L}^{\mathbf{1 , 3}}\right)$ or propyl $\left(\mathbf{G d L}^{2,4}\right)$ side arms, suggesting very specific coordination properties among pairs of these systems (Table 2). Namely, 


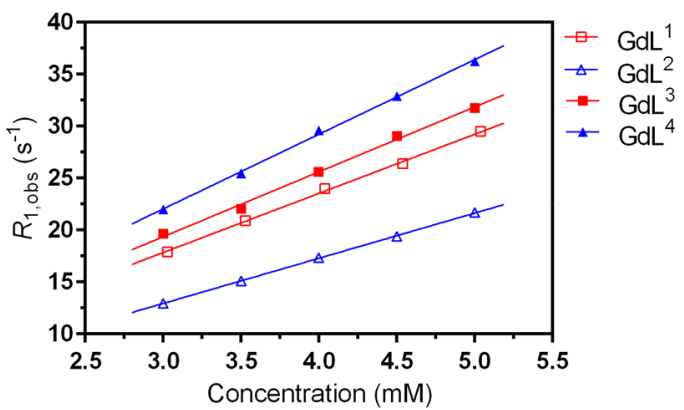

Figure 3. Determination of the longitudinal relaxivity for $\mathbf{G d L}^{1-4}$ at 7 $\mathrm{T}, 25{ }^{\circ} \mathrm{C}$, and $\mathrm{pH} 7.4$ (HEPES).

Table 2. Longitudinal Relaxivities of $\mathrm{GdL}^{1-4}$ at $7 \mathrm{~T}, 25^{\circ} \mathrm{C}$, and $\mathrm{pH} 7.4$ (HEPES)

$\begin{array}{cc}\text { complex } & r_{1}\left(\mathrm{mM}^{-1} \mathrm{~s}^{-1}\right) \\ \mathbf{G d L}^{1} & 5.69 \pm 0.12 \\ \mathbf{G d L}^{2} & 4.35 \pm 0.04 \\ \mathbf{G d L}^{3} & 6.25 \pm 0.24 \\ \mathbf{G d L}^{4} & 7.19 \pm 0.17\end{array}$

the $r_{1}$ value of around $5.7 \mathrm{mM}^{-1} \mathrm{~s}^{-1}$ for $\mathbf{G d L}^{1}$ that is supposed to mimic the previously studied SCAs in the absence of $\mathrm{Ca}^{2+}$ is much higher than the usual initial relaxivity of these systems (3.0-3.5 $\left.\mathrm{mM}^{-1} \mathrm{~s}^{-1}\right)$. The vicinity of the positively charged amine group due to the shorter ethyl linker in $\mathbf{G d L}^{1}$ which was previously discussed (see above) and its possible repulsion with the positively charged paramagnetic metal center is likely preventing efficient coordination of the carboxylate group to the metal ion. Consequently, the hydration of $\mathbf{G d L}^{1}$ is higher than in the SCA analogues and hence also the $r_{1}$ value. A slight increase in $r_{1}$ for $\mathrm{GdL}^{3}$ speaks in favor of this observation-this complex without a carboxylate group (and possibility to coordinate to $\mathrm{Gd}^{3+}$ with the side linker) has coordination properties similar to those of $\mathbf{G d L}^{1}$, which leads to the conclusion that in neither of the complexes with ethyl linkers do the side arms coordinate to the metal center.

On the other hand, the $r_{1}$ values observed for complexes with the propyl linkers $\left(\mathbf{G d L}^{2,4}\right)$ can be much better correlated to those of the SCAs. Here the difference in relaxivities of almost 3 $\mathrm{mM}^{-1} \mathrm{~s}^{-1}$ between $\mathbf{G d L}^{2}$ and $\mathbf{G d L}^{4}$ indicates substantial differences in their coordination properties: the elongation of the distance between the positively charged amine and metal center allows for better interaction of the carboxylate group with $\mathrm{Gd}^{3+}$, resulting in lower hydration and hence the relaxivity in $\mathbf{G d L}^{2}$. Similarly, the hydration of the metal center in $\mathbf{G d L}^{4}$ is likely improved due to the same reasons (absence of the carboxylate group concurrently combined with a longer distance between the amine group and $\mathrm{Gd}^{3+}$ ), which reflects on the $r_{1}$ value (it exceeds $7 \mathrm{mM}^{-1} \mathrm{~s}^{-1}$ ), thus matching the $r_{1}$ values of many Ca-saturated SCAs that were previously developed by us. ${ }^{4}$ However, one should note that, despite several similarities between $\mathbf{G d L}^{1-4}$ and previously studied $\mathrm{SCAs}^{4}$ the former do not mimic the SCA behavior to a greater extent, probably due to small but important structural differences of the amine groups from the side chain, which is reflected in protonation and consequently the coordination properties.

The ${ }^{1} \mathrm{H}$ NMR spectra of the $\mathrm{Eu}^{3+}$ complexes of $\mathbf{L}^{3}$ and $\mathbf{L}^{4}$ were recorded in $\mathrm{D}_{2} \mathrm{O}$ solutions $(30 \mathrm{mM})$ at $\mathrm{pD}$ 9. The spectra show relatively sharp resonances that spread over the range $\sim-25$ to $+40 \mathrm{ppm}$ due to the paramagnetic shifts induced by the metal ion (Figure 4). It is well-established that DOTA-like

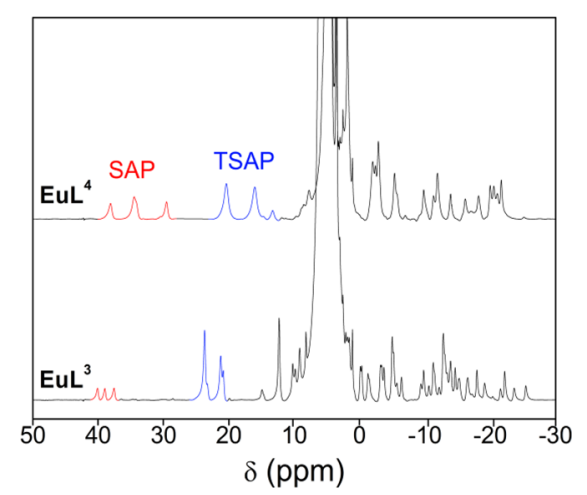

Figure 4. ${ }^{1} \mathrm{H}$ NMR spectra $(300 \mathrm{MHz})$ of the $\mathbf{E u L}^{3}$ and $\mathbf{E u L}^{4}$ complexes recorded in $\mathrm{D}_{2} \mathrm{O}$ solution at $298 \mathrm{~K}$ ( $\mathrm{pD} 9.0$ ).

complexes may exist in solution as two different diastereoisomers, providing either an SAP or a TSAP coordination around the lanthanide(III) ion. These isomers differ either in the orientation of the pendant arms of the macrocycle, which is often denoted as $\Delta$ or $\Lambda$, or the conformation of the cyclen moiety $(\delta \delta \delta \delta$ or $\lambda \lambda \lambda \lambda){ }^{31,32}$ In $\mathrm{Eu}^{3+}$ complexes of DOTA and DO3A derivatives, the signals of the pseudoaxial protons on the cyclen rings are usually found between 24 and $45 \mathrm{ppm}$ in the SAP isomer and below 25 ppm in the TSAP isomer. ${ }^{33-38}$ The spectrum of the $\mathrm{EuL}^{4}$ complex shows these signals in the range 30-40 ppm, although additional signals in the range 15-23 ppm suggest the presence of an important TSAP population as well (Figure 4). A rough estimation from signal integration suggests approximately equal populations of the SAP and TSAP isomers. The ${ }^{1} \mathrm{H}$ NMR spectrum of the paramagnetic $\mathbf{Y b L}^{4}$ complex is also relatively well resolved (Figure S15 in the Supporting Information). It shows paramagnetically shifted signals from ca. -100 to $140 \mathrm{ppm}$. The four signals of the axial protons of the cyclen unit pointing to the hydrophobic side of the complex are observed at 134.5, 119.6, 108.2, and 105.6 ppm. The chemical shifts of these signals are characteristic of a SAP coordination geometry around the two metal ions by comparison with related compounds. ${ }^{39-41}$ Thus, the relative population of the SAP isomer increases from $\mathrm{Eu}^{3+}$ (ca. 50\%) to $\mathrm{Yb}^{3+}(100 \%)$, in line with a stabilization of the SAP isomer on proceeding across the lanthanide series observed for a related system.

The spectrum of $\mathrm{EuL}^{3}$ also presents two sets of signals due to the pseudoaxial protons. The signals of the axial protons of the SAP isomer are observed in the range $37-40 \mathrm{ppm}$ and present a lower intensity with respect to those of the TSAP isomer, which are observed between ca. 21 and 24 ppm. The relative intensity of the signals due to TSAP and SAP isomers point to a 2.8:1 (TSAP:SAP) isomer ratio. Thus, increasing the length of the spacer joining the cyclen unit and the amide group of the side chain provokes a stabilization of the SAP isomer, likely due to an increased steric hindrance introduced by the bulkier pendant arm. ${ }^{42}$ Nevertheless, the complex of $\mathbf{E u L}^{3}$ presents a significant population of the hydroxide species at the $\mathrm{pH}$ used for NMR studies (Figure 2), and thus the different isomeric compositions of $\mathbf{E u L}^{3}$ and $\mathrm{EuL}^{4}$ might also be related to a higher abundance of the $[\mathrm{EuL}(\mathrm{OH})]^{-}$species in the former.

Additional structural information was gained by recording the emission spectra of the $\mathrm{Eu}^{3+}$ complexes. Considering the 
lack of suitable chromophoric units for the indirect excitation of the metal ion through the antenna effect, emission spectra were recorded using rather concentrated solutions $\left(10^{-3} \mathrm{M}\right)$ with direct excitation of the metal ion at $395 \mathrm{~nm}\left({ }^{5} \mathrm{~L}_{6} \leftarrow{ }^{7} \mathrm{~F}_{0}\right.$ transition $).{ }^{43}$ The corresponding emission spectra display the typical ${ }^{5} \mathrm{D}_{0} \rightarrow{ }^{7} \mathrm{~F}_{\mathrm{J}}$ transitions of $\mathrm{Eu}^{3+}(\mathrm{J}=0-4$, Figure 5$)$. The

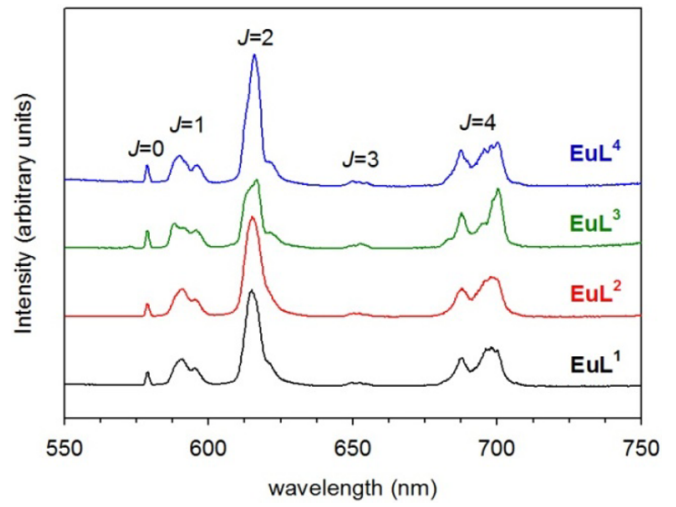

Figure 5. Emission spectra of the $\mathrm{Eu}^{3+}$ complexes recorded from $10^{-3}$ M solutions under excitation at $395 \mathrm{~nm}(\mathrm{pH} 8.5)$.

emission spectra of the complexes $\mathbf{E u L}^{1}, \mathbf{E u L}^{2}$, and $\mathbf{E u L}^{4}$ are very similar, pointing to similar coordination environments around the metal ion. In particular, the intensity of the ${ }^{5} \mathrm{D}_{0} \rightarrow$ ${ }^{7} \mathrm{~F}_{1}$ transition is relatively independent of the ligand environment due to its magnetic dipole character, while the electric dipole ${ }^{5} \mathrm{D}_{0} \rightarrow{ }^{7} \mathrm{~F}_{2}$ transition is very sensitive to changes in the coordination environment. The complexes $\mathbf{E u L}^{\mathbf{1}}, \mathbf{E u L}{ }^{2}$, and $\mathrm{EuL}^{4}$ present very similar $(\Delta J=2):(\Delta J=1)$ intensity ratios, in line with similar solution structures, while the $(\Delta J=2):(\Delta J=$ 1) intensity ratio is clearly different for $\mathbf{E u L}^{3}$ (Table 3), ${ }^{44}$ which

Table 3. Photochemical Properties of the Complexes $\mathrm{EuL}^{1-4 a}$

$\begin{array}{lcccccc} & \mathrm{pH} & \Delta J=2: \Delta J=1^{b} & \tau_{\mathrm{H}_{2} \mathrm{O}} / \mathrm{ms}^{c} & \tau_{\mathrm{D}_{2} \mathrm{O}} / \mathrm{ms}^{c} & q^{d} & q^{e} \\ \text { EuL }^{1} & 8.4 & 3.0 & 0.512 & 1.90 & 1.3 & 1.2 \\ & 6.6 & 2.5 & 0.317 & 1.70 & 2.8 & 2.5 \\ \text { EuL }^{2} & 8.4 & 3.1 & 0.504 & 2.23 & 1.4 & 1.3 \\ & 6.5 & 2.6 & 0.330 & 1.61 & 2.6 & 2.3 \\ \text { EuL }^{3} & 8.4 & 2.3 & 0.516 & 1.80 & 1.3 & 1.1 \\ & 5.4 & 2.5 & 0.386 & 1.57 & 2.0 & 1.8 \\ \text { EuL }^{4} & 8.4 & 2.8 & 0.597 & 1.63 & 0.9 & 0.7 \\ & 6.7 & 2.8 & 0.368 & 1.70 & 2.3 & 2.0\end{array}$

${ }^{a} \lambda_{\text {exc }} 395 \mathrm{~nm} .{ }^{b}$ Relative intensity of the ${ }^{5} \mathrm{D}_{0} \rightarrow{ }^{7} \mathrm{~F}_{2}$ and ${ }^{5} \mathrm{D}_{0} \rightarrow{ }^{7} \mathrm{~F}_{1}$ transitions. ${ }^{c}$ Emission lifetimes; estimated error $\pm 10 \%$. ${ }^{d}$ Calculated according to ref 45 . ${ }^{e}$ Calculated according to ref 46 .

is in line with the NMR spectra of $\mathrm{EuL}^{3}$ and $\mathrm{EuL}^{4}$ showing a different ratio of the SAP and TSAP isomers in solution. This might be related again to the rather different speciation of $\mathbf{E u L}^{3}$ with respect to the other three complexes at $\mathrm{pH} 8.5$ (see Figure 2).

The lifetimes of the ${ }^{5} \mathrm{D}_{0}$ excited states of $\mathrm{Eu}^{3+}$ were measured in solutions of the complexes in $\mathrm{H}_{2} \mathrm{O}$ and $\mathrm{D}_{2} \mathrm{O}$ at $\mathrm{pH} 8.5$ to determine the number of water molecules coordinated to the metal ion (Table 3). The lifetimes measured in $\mathrm{H}_{2} \mathrm{O}$ solutions for the four complexes are very similar, falling within the range 0.5-0.6 ms. These values are shorter than those measured for the responsive agents containing $\mathrm{Ca}^{2+}$ chelating units, ${ }^{6}$ pointing to increased hydration numbers and certain but important differences in coordination chemistry and hence the behavior of the responsive and analogous model systems. This is confirmed by the hydration numbers calculated according to the methods developed by Parker ${ }^{45}$ and Horrocks, ${ }^{46}$ which predict hydration numbers of about 1 for the four complexes.

The hydration numbers obtained from lifetime measurements indicate coordination of the amide pendant arm to the metal ion, nine-coordination being completed by an innersphere water molecule. This indicates that the carboxylate groups of the amide arms in $\mathbf{E u L}^{1}$ and $\mathbf{E u L}^{2}$ are not coordinating to the metal ion, which can be supported by DFT calculations, as they predict rather short $\mathrm{Eu}-\mathrm{O}_{\text {amide }}$ distances in comparison to those involving the carboxylate oxygen atoms (Figure 6; see also Figures S16-S18 in the
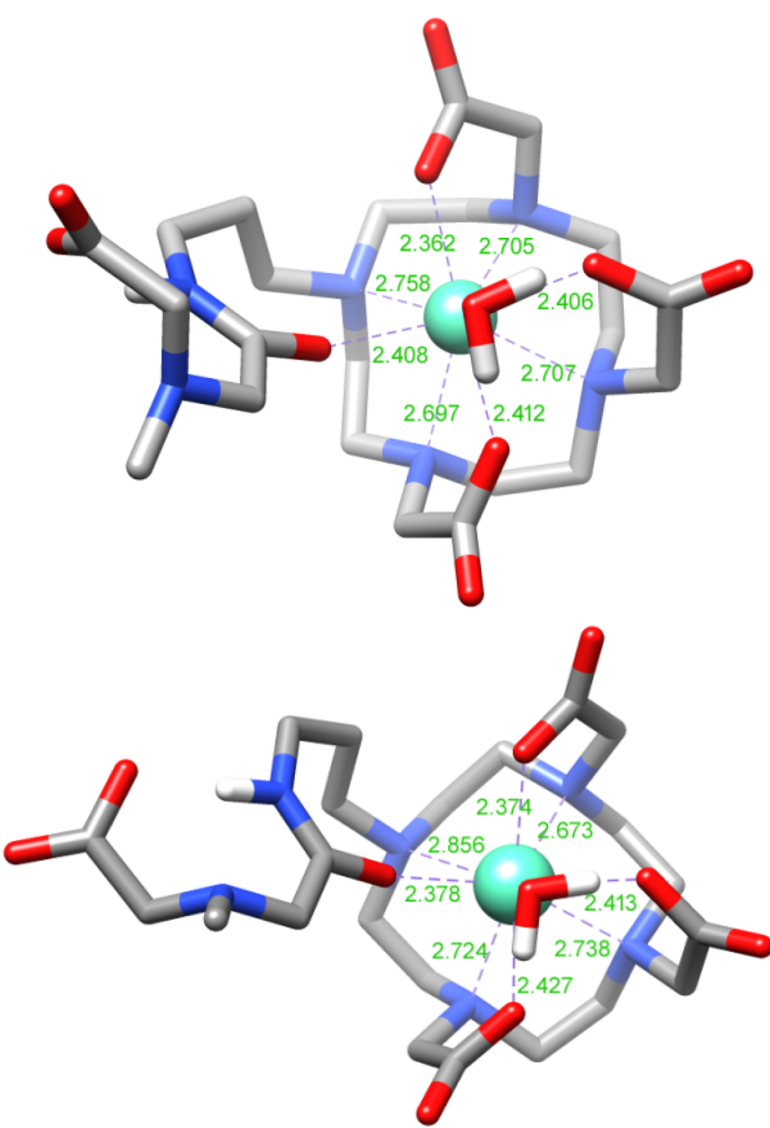

Figure 6. Molecular geometries of the SAP (top) and TSAP (bottom) isomers of the $\mathrm{EuL}^{2}$ complex obtained with DFT calculations. Hydrogen atoms are omitted for simplicity. Bond distances are given in $\AA$.

Supporting Information). The lack of coordination of the carboxylate group of the amide pendant in $\mathrm{EuL}^{1}$ and $\mathrm{EuL}^{2}$ is in contrast to the behavior of the responsive $\mathrm{Ca}^{2+}$ and $\mathrm{Zn}^{2+}$ contrast agents reported before, ${ }^{8,15}$ which showed a relaxivity increase associated with an increased hydration number (from $q$ $=0$ to $q=1$ ) in the presence of the divalent metal ion and partially to the obtained $r_{1}$ value for $\mathbf{G d L}^{2}$ (see above). On the other hand, the results match well to properties obtained for $\mathbf{G d L}^{2}$, which exhibited a higher $r_{1}$ value (see above). The $\mathrm{OFF}-\mathrm{ON}$ relaxivity responses are probably related to the weak binding of the remote carboxylate group occupying a capping position in the coordination polyhedron, ${ }^{47}$ whereas all the 
investigated responsive and model systems ( $\mathbf{S C A}^{\mathbf{1 , 2}}$ and Gd/ $\mathrm{EuL}^{1-4}$, respectively) present coordinations that are right on the edge regarding this particular aspect, thus displaying different properties depending on other surrounding factors. Consequently, subtle changes in the ligand structure may favor the noncoordination of the carboxylate at the apical position.

Protonation of the terminal amine group in the amide side chain results in a noticeable shortening of the emission lifetimes (Table 3), which indicates further changes in coordination properties of $\mathbf{E u L}^{1-4}$ and possible decoordination of the amide group from the metal ion under these conditions. This is confirmed by the $q$ values obtained from luminescence lifetime measurements at $\mathrm{pH} \sim 6$, where the protonated species dominates the overall solution speciation. The hydration numbers obtained under these conditions are close to 2 , as expected for complexes with heptadentate DO3A derivatives, and are in line with observations made with $\mathbf{G d L}^{\mathbf{1 - 4}}$ and their $r_{1}$ values at low magnetic fields (Figure 2). Thus, the repulsive electrostatic interaction involving the metal ion and the protonated amine nitrogen atom provokes the decoordination of the amide group, which reflects directly on the $r_{1}$ values.

Dissociation of the $\mathrm{GdL}^{1-4}$ Complexes. Different studies reported in the past several years demonstrated that the kinetic inertness of in vivo applied Gd-based agents is more important than their thermodynamic stability, as slow dissociation kinetics ensures that the complex remains intact until the excretion through the kidneys. ${ }^{48}$ Thus, it is very important to ensure that SCAs also possess sufficient inertness for their wider and routine in vivo application. On the other hand, dissociation kinetics data of the recently reported SCAs based on $\mathrm{Gd}^{3+}$ are scarce. $^{2,49}$ For instance, the Caravan group has recently highlighted that the use of macrocyclic platforms does not necessarily guarantee the kinetic inertness of the complexes of DO3A-like ligands. It was also shown that the side arms attached to the macrocycle can have a noticeable effect on the rates of dissociation, so that the inertness can decrease upon $\mathrm{N}$ alkylation despite higher ligand denticity. ${ }^{50}$ With this in mind, the dissociation kinetics of the $\mathrm{Gd}^{3+}$ complexes formed with the $\mathbf{L}^{1-4}$ model compounds was studied, aiming to investigate the effect of the linear pendant arms bound to the DO3A platform on the inertness of these complexes.

It is known that dissociation of the metal complexes in vivo can be promoted either by endogenous metal ions such as $\mathrm{Ca}^{2+}$, $\mathrm{Zn}^{2+}$, and $\mathrm{Cu}^{2+}$ or by endogenous ligands such as citrate, phosphate, and carbonate. ${ }^{1,51}$ Therefore, the characterization of the kinetic inertness of $\mathrm{Gd}^{3+}$ complexes is usually carried out using metal exchange reactions with $\mathrm{Zn}^{2+}$ (relaxometric method) or with $\mathrm{Cu}^{2+}$ (spectrophotometric method) as exchanging partners. In these reactions, the competing metal ion is applied in at least 10-fold excess to ensure the pseudofirst-order conditions. In our study, the dissociation reactions of $\mathrm{GdL}^{1-4}$ were studied in the presence of high excess (10-40fold) of the $\mathrm{Cu}^{2+}$ ion (Figure 7 and Figures S19 and S20 in the Supporting Information).

The rate of such a reaction can be expressed by eq 4, where $k_{\mathrm{d}}$ is the pseudo-first-order rate constant and $[\mathrm{GdL}]_{\text {tot }}$ is the total concentration of the $\mathrm{Gd}^{3+}$ complex.

$$
-\frac{\mathrm{d}[\mathrm{GdL}]}{\mathrm{d} t}=k_{\mathrm{d}}[\mathrm{GdL}]_{\mathrm{tot}}
$$

The exchange reactions were executed in the $\mathrm{pH}$ range $3-5$, so that the $\mathrm{GdL}^{\mathbf{1 - 4}}$ complexes are present in solution mainly in monoprotonated form (Figure 2). The dissociation reactions of
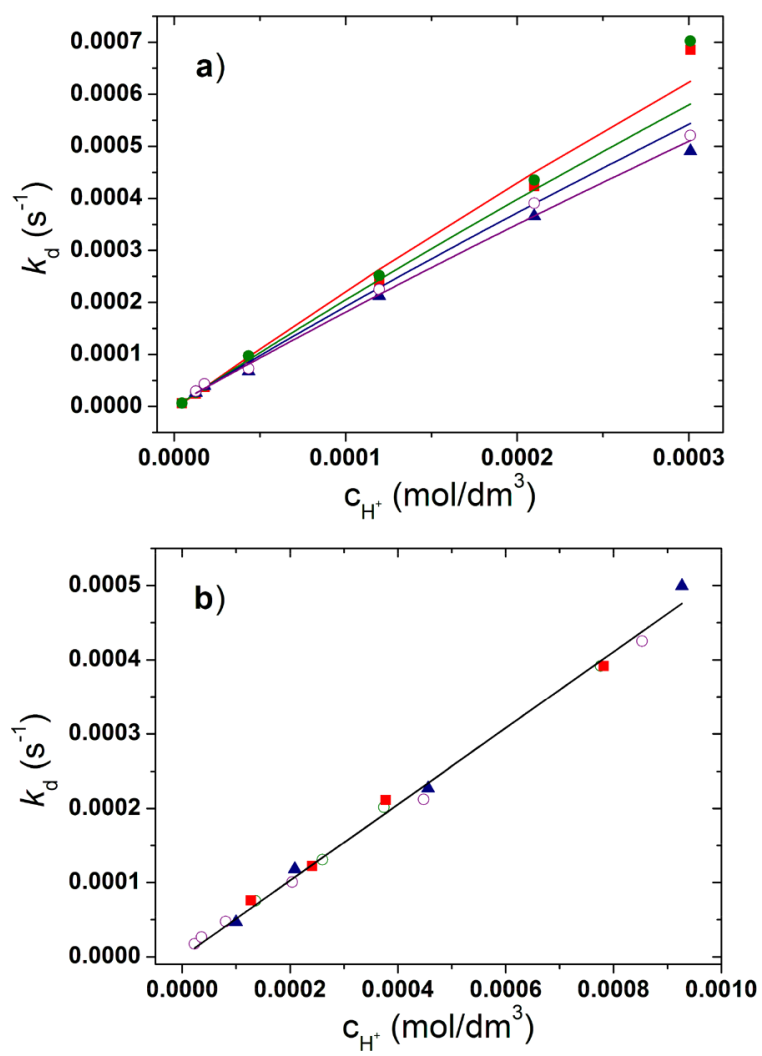

Figure 7. Dependence of the pseudo-first-order rate constants $\left(k_{\mathrm{d}}\right)$ on the concentration of $\mathrm{H}^{+}$ions for the metal exchange reaction between $\mathbf{G d L}^{2}$ (a) and $\mathbf{G d L}^{3}$ (b) complexes and the $\mathrm{Cu}^{2+}$ ion. The excess of $\mathrm{Cu}^{2+}$ ion was $\times 10$-fold (purple $\mathrm{O}$ ), $\times 20$-fold (blue $\mathbf{\Delta}$ ), $\times 30$-fold (green $\mathbf{0}$ ), and $\times 40$-fold (red $\boldsymbol{\square}$ ). The solid lines correspond to the fits of the data as described in the text.

the $\mathrm{Gd}^{3+}$ complexes can mainly occur via spontaneous, protonassisted, metal-assisted and proton-metal-assisted pathways (Scheme 2). ${ }^{1}$

Scheme 2. Reaction Mechanisms Responsible for the Dissociation of $\mathrm{Gd}^{3+}$ Complexes ${ }^{a}$

$$
\mathrm{Gd}^{3+}+\mathrm{H}_{\mathrm{n}}
$$

${ }^{a}$ Charges are omitted for clarity.

The rate constants $k_{0}, k_{\mathrm{H}}, k_{\mathrm{H}}{ }^{\mathrm{H}}, k_{\mathrm{M}}$, and $k_{\mathrm{M}}{ }^{\mathrm{H}}$ characterize the rates of the spontaneous, proton-assisted, metal-assisted, and proton-metal-assisted (when the exchanging metal attacks the protonated complexes) reaction pathways, respectively. In addition, $K_{\mathrm{GdHL}}, K_{\mathrm{GdH} 2 \mathrm{~L}}$, and $K_{\mathrm{GdLM}}$ are the protonation constants of the complexes $[\mathrm{Gd}(\mathrm{HL})]$ and $\left[\mathrm{Gd}\left(\mathrm{H}_{2} \mathrm{~L}\right)\right]$ and the stability constant of the mixed dinuclear complexes $[\mathrm{Gd}(\mathrm{L}) \mathrm{M}]$, respectively.

Taking into account the different reaction pathways in Scheme 2 and the equations determining the $K_{\mathrm{GdHL}}, K_{\mathrm{GdH} 2 \mathrm{~L}}$, and $K_{\mathrm{GdLM}}$ equilibrium constants, the pseudo-first-order rate 
Table 4. Rate Constants Characterizing the Dissociation of the $\mathrm{Gd}^{3+}$ Complexes of $\mathrm{L}^{1-4}$, DTPA, DO3A, EAEA-DO3A, and EAPA-DO3A Ligands ${ }^{a}$

\begin{tabular}{|c|c|c|c|c|c|c|c|c|}
\hline & $L^{1}$ & $\mathrm{~L}^{2}$ & $\mathbf{L}^{3}$ & $\mathrm{~L}^{4}$ & $\mathrm{DO}_{3} \mathrm{~A}^{b}$ & DTPA $^{c}$ & EAEA-DO3A ${ }^{d}$ & EAPA-DO3A $^{d}$ \\
\hline$k_{1}\left(\mathrm{M}^{-1} \mathrm{~s}^{-1}\right)$ & $0.4 \pm 0.1$ & $2.6 \pm 0.2$ & $0.53 \pm 0.02$ & $3.2 \pm 0.1$ & 0.023 & 0.58 & $2.6 \times 10^{-6}$ & $2.1 \times 10^{-3}$ \\
\hline$k_{2}\left(\mathrm{M}^{-1} \mathrm{~s}^{-1}\right)$ & & & & & & & $3.1 \times 10^{-5}$ & $3.5 \times 10^{-2}$ \\
\hline$K_{\mathrm{GdH} 2 \mathrm{~L}}\left(\mathrm{M}^{-1}\right)$ & $106 \pm 43$ & $466 \pm 389$ & & & & 100 & 3.1 & 15 \\
\hline$k_{3}\left(\mathrm{M}^{-1} \mathrm{~s}^{-1}\right)$ & & $(1.2 \pm 0.5) \times 10^{-3}$ & & & & 0.93 & & \\
\hline$K_{\mathrm{GdLM}}\left(\mathrm{M}^{-1}\right)$ & $100 \pm 33$ & $39 \pm 16$ & & & & 13 & & \\
\hline$k_{\mathrm{obs}}$ at $\mathrm{pH} 6.0^{e}$ & $4 \times 10^{-7}$ & $2.6 \times 10^{-6}$ & $5.3 \times 10^{-7}$ & $3.2 \times 10^{-6}$ & $2.3 \times 10^{-8}$ & $9.9 \times 10^{-6}$ & $2.6 \times 10^{-12}$ & $2.1 \times 10^{-9}$ \\
\hline$t_{1 / 2}\left(\mathrm{~s}^{-1}\right)$ at $\mathrm{pH} 6.0^{e}$ & 481.4 & 73.8 & 363.3 & 60.2 & $8.4 \times 10^{3}$ & 19.5 & $7.4 \times 10^{7}$ & $9.2 \times 10^{4}$ \\
\hline
\end{tabular}

${ }^{a}$ Conditions: $25{ }^{\circ} \mathrm{C}, I=0.15 \mathrm{M} \mathrm{NaCl} .{ }^{b}$ Reference $16 .{ }^{c}$ Reference $51 .{ }^{d}$ Reference $17 .{ }^{e}$ The concentration of the $\mathrm{Cu}^{2+}$ used in the calculation was 10 $\mu \mathrm{M}$.

constant $\left(k_{\mathrm{d}}\right)$ can be then expressed by eq 5 , where $K_{\mathrm{GdHL}}=$ $[\mathrm{Gd}(\mathrm{HL})] /[\mathrm{Gd}(\mathrm{L})]\left[\mathrm{H}^{+}\right], K_{\mathrm{GdH} 2 \mathrm{~L}}=\left[\mathrm{Gd}\left(\mathrm{H}_{2} \mathrm{~L}\right)\right] /[\mathrm{Gd}(\mathrm{HL})]-$ $\left[\mathrm{H}^{+}\right], K_{\mathrm{GdLM}}=[\mathrm{Gd}(\mathrm{L}) \mathrm{M}] /[\mathrm{Gd}(\mathrm{L})][\mathrm{M}], k_{1}=k_{\mathrm{H}} K_{\mathrm{GdHL}}, k_{2}=$ $k_{\mathrm{H}}{ }^{\mathrm{H}} K_{\mathrm{GdHL}} K_{\mathrm{GdH} 2 \mathrm{~L}}, k_{3}=k_{\mathrm{M}} K_{\mathrm{GdLM}}$, and $k_{4}=k_{\mathrm{M}}{ }^{\mathrm{H}} K_{\mathrm{GdLM}}$.

$$
k_{\mathrm{d}}=\frac{k_{0}+k_{1}\left[\mathrm{H}^{+}\right]+k_{2}\left[\mathrm{H}^{+}\right]^{2}+k_{3}\left[\mathrm{M}^{n+}\right]+k_{4}\left[\mathrm{M}^{n+}\right]\left[\mathrm{H}^{+}\right]}{1+K_{\mathrm{GdHL}}\left[\mathrm{H}^{+}\right]+K_{\mathrm{GdH}_{2} \mathrm{~L}}\left[\mathrm{H}^{+}\right]^{2}+K_{\mathrm{GdLM}}\left[\mathrm{M}^{n+}\right]}
$$

Equation 5 is a general equation for describing the rates of the metal exchange reactions. The $k_{\mathrm{d}}$ values of the metal exchanging reactions increase with increasing of the $\mathrm{H}^{+}$ concentration in all cases (Supporting Information), while the metal-assisted pathway plays a role only in the dechelation reaction of $\mathbf{G d L}^{2}$ (Figure 7). Considering these facts, eq 5 can be simplified to eqs $6-8$ for $\mathbf{G d L}^{2}, \mathbf{G d L}^{\mathbf{1}}$, and $\mathbf{G d L}^{3,4}$ complexes, respectively.

$$
\begin{aligned}
& k_{\mathrm{d}}=\frac{k_{0}+k_{1}\left[\mathrm{H}^{+}\right]+k_{3}\left[\mathrm{M}^{n+}\right]}{1+K_{\mathrm{GdHL}}\left[\mathrm{H}^{+}\right]+K_{\mathrm{GdLM}}\left[\mathrm{M}^{n+}\right]} \\
& k_{\mathrm{d}}=\frac{k_{0}+k_{1}\left[\mathrm{H}^{+}\right]}{1+K_{\mathrm{GdHL}}\left[\mathrm{H}^{+}\right]+K_{\mathrm{GdLM}}\left[\mathrm{M}^{n+}\right]} \\
& k_{\mathrm{d}}=\frac{k_{0}+k_{1}\left[\mathrm{H}^{+}\right]}{1+\mathrm{K}_{\mathrm{GdHL}}\left[\mathrm{H}^{+}\right]}
\end{aligned}
$$

The proton-assisted dissociation processes mostly occur by a proton transfer from a protonated side arm to the nitrogen atom of the macrocyclic ring, followed by the release of the $\mathrm{Gd}^{3+}$ ion from the coordination cavity. In the metal-assisted decomplexation reaction, the exchanging metal attacks the complex directly, forming the dinuclear intermediate $[\mathrm{Gd}(\mathrm{L})$ $\mathrm{M}$ ], which dissociates to $\mathrm{Gd}^{3+}$ ion and a $\mathrm{ML}$ complex. The kinetic parameters were obtained for $\mathrm{GdL}^{1-4}$ from the fits of the $k_{\mathrm{d}}$ values and were compared with those for $[\mathrm{Gd}(\mathrm{DO} 3 \mathrm{~A})]$, $[\mathrm{Gd}($ EAEA-DO3A $)], \quad[\mathrm{Gd}($ EAPA-DO3A $)]$, and $[\mathrm{Gd}-$ (DTPA $)]^{2-}$ that were previously reported in the literature (Table 4). ${ }^{17,18,52}$

During the fitting process, $k_{0}$ values characterizing the spontaneous dissociation were found to be negligible in all cases, suggesting the insignificant role of spontaneous dissociation in the dissociation of the monoprotonated $[\mathrm{Gd}(\mathrm{HL})]$ complexes. The values of $K_{\mathrm{GdH} 2 \mathrm{~L}}$ constants for $\left[\mathrm{Gd}\left(\mathbf{L}^{3}\right)\right]$ and $\left[\mathrm{Gd}\left(\mathbf{L}^{4}\right)\right]$ were lower than their standard deviation and therefore were omitted during the fitting procedure. The proton-assisted dissociation rates of $\left[\mathrm{Gd}\left(\mathbf{L}^{1}\right)\right]$ and $\left[\mathrm{Gd}\left(\mathbf{L}^{3}\right)\right]$ are comparable with that of $[\mathrm{Gd}(\mathrm{DTPA})]^{2-}$ and one order of magnitude higher than for $[\mathrm{Gd}(\mathrm{DO} 3 \mathrm{~A})]$. Both $\left[\mathrm{Gd}\left(\mathrm{L}^{2}\right)\right]$ and $\left[\mathrm{Gd}\left(\mathrm{L}^{4}\right)\right]$ dissociate a few times faster than
$[\mathrm{Gd}(\mathrm{DTPA})]^{2-}$. The faster dissociation of $\left[\mathrm{Gd}\left(\mathbf{L}^{\mathbf{1 - 4}}\right)\right]$ complexes in comparison to $[\mathrm{Gd}(\mathrm{DO} 3 \mathrm{~A})]$ indicates that the presence of the amine-containing pendant (protonated under the used experimental conditions) notably decreases the kinetic inertness of the corresponding complexes. Obviously, the presence of an exocyclic amine prone to protonation cannot be compared with examples of cyclen-based ligands (e.g., $\mathrm{Ln}^{3+}$ complexes of DOTA-gly 4 , DO3A-picolinate, or DO3AP ligands) where the presence of protonation sites in the complexes (carboxylate groups) did not result in a notable acceleration of the dissociation rates. ${ }^{53-56}$

The relatively fast dissociation kinetics of $\mathrm{GdL}^{1-4}$ complexes are obviously related to the presence of a protonation site in the amide side chain of the ligand, as previously reported for the $\mathrm{Gd}^{3+}$ complexes of the aryl-phosphonate derivatives of DO3A. ${ }^{57}$ Protonation of the amine group of the pendant arm may promote proton transfer to the macrocycle, forming an intermediate in which the electrostatic repulsion between the protonated group and the $\mathrm{Gd}^{3+}$ ion triggers complex dissociation. The relatively low protonation constants $\left(K_{\mathrm{GdH} 2 \mathrm{~L}}\right)$ of the $\left[\mathrm{Gd}\left(\mathrm{HL}^{1,2}\right)\right]$ species (Table 4) indicate that the protonation in these complexes is likely occurring at a carboxylate group.

The difference in the kinetic inertness of the $\left[\mathrm{Gd}\left(\mathrm{L}^{1,3}\right)\right]$ and $\left[\mathrm{Gd}\left(\mathrm{L}^{2,4}\right)\right]$ complexes obviously results from the length of the linker used to tie the pendant arm to the macrocyclic platform. This is rather interesting, since the amide pendant arm is not coordinated to the metal ion in the protonated complex (or in the dinuclear kinetic intermediate $[\mathrm{Gd}(\mathrm{L}) \mathrm{Cu}]$ that forms immediately upon mixing of the components for $\mathbf{L}^{1}$ and $\mathbf{L}^{2}$ ). Perhaps the higher flexibility of the propyl linker of $\mathbf{L}^{2}$ and $\mathbf{L}^{4}$ facilitates the approximation of the protonated amine group to an acetate pendant arm, triggering a cascade of proton transfer events that eventually results in complex dissociation.

The involvement of the dinuclear intermediates in the metal exchange reactions of $\mathbf{G d L}^{\mathbf{1}}$ and $\mathbf{G d L}^{2}$ suggests the coordination of the $\mathrm{Cu}^{2+}$ ion (formation of the dinuclear intermediate) to the 2-(methylamino) acetate group. The transformation of these intermediates to the products of the reaction $\left(\mathrm{Cu}^{2+}\right.$ complex and free $\left.\mathrm{Gd}^{3+}\right)$ is hindered, as this pathway has little effect on the rates of dissociation in the case of $\mathbf{L}^{2}$, whereas it was proved to be a dead-end complex for GdL ${ }^{1}$.

Owing to the different mechanisms responsible for the dissociation of $\mathbf{G d L}^{1-4}$ complexes, we have calculated their halflives $\left(t_{1 / 2}\right)$ of dissociation at $\mathrm{pH} 6.0$ for comparison purposes (Table 4). The $\mathrm{pH}$ for the calculation was selected by keeping in mind that at $\mathrm{pH} 6.0$ the $\mathrm{Gd}\left(\mathrm{HL}^{1-4}\right)$ complexes are quantitatively present in solution, while partial deprotonation 
of amine nitrogens occurs near $\mathrm{pH} 7.4$, resulting in the formation of $\mathbf{G d L}^{1-4}$ species. The results obtained show that the dissociation half-lives $\left(t_{1 / 2}\right)$ of $\mathbf{G d L}^{\mathbf{1 - 4}}$ are lower than for analogous DO3A or DOTA-type complexes but are still higher than those for $[\mathrm{Gd}(\mathrm{DTPA})]^{2-}$ (Table 4).

\section{CONCLUSIONS}

Herein we have presented a very detailed characterization of the thermodynamic stability and inertness of a series of DO3A derivatives that were designed as model compounds of an efficient family of responsive MRI contrast agents. However, these "simple" model systems were found to behave differently with respect to the parent, responsive probes. For instance, the longitudinal relaxivities of $\mathbf{G d L}^{1-4}$ did not completely match those observed for SCA analogues, partially as the carboxylate group present in the amide side arm of $\mathbf{G d L}^{1}$ or $\mathbf{G d L}^{2}$ is not involved in the metal ion binding. We also found that protonation of the side chains of the ligands occurs at a rather high $\mathrm{pH}$, provoking decoordination of the amide group. The protonation of the amide group is detrimental to the stability of the complexes in solution due to the electrostatic interaction between the protonated amine group and the metal ion. However, we want to highlight that the constants characterizing the protonation of the amine group $\left(\log K_{\mathrm{GdL} \times \mathrm{H}}=7.2-8.1\right)$ are higher than the first protonation constant of a EGTA-bisamide metal binding unit $(6.6-6.8),{ }^{58}$ which is the typical Ca-binding moiety present in the responsive chelates. Thus, the $\mathrm{Ca}$ responsive CAs are likely not protonated under physiological conditions, which is expected to improve their stability profile. Moreover, this difference in protonation constants may have very important consequences on the interaction of the pendant arm with the metal center and hence the hydration of the complex and its relaxivity.

The protonation of the amine nitrogen of the pendant arm also likely triggers proton-assisted dissociation of the complexes. Nevertheless, dissociation experiments were performed for the monoprotonated complexes, and one cannot directly extrapolate these results to the $\left[\mathrm{Gd}\left(\mathrm{L}^{1-4}\right)\right]$ complexes, which are expected to have better dissociation kinetic properties.

The results obtained for the $\mathrm{GdL}^{1-4}$ complexes afforded a collection of valuable information for the future design of responsive probes. They also provide clear strategies to improve the stability profiles of Gd-based MRI contrast agents. Complexes with better stability profiles should avoid the presence of basic sites close to the Gd-binding unit, as this is clearly detrimental to the thermodynamic stability and kinetic inertness of the complex. While improving these properties is important for application in humans, the responsive agents developed in previous works have kinetic profiles likely superior to that of $[\mathrm{Gd}(\mathrm{DTPA})]^{2-}$ (which is commonly used in clinical practice) and thus likely they can be safely applied in animal studies.

\section{EXPERIMENTAL AND COMPUTATIONAL SECTION}

Equilibrium Measurements. The chemicals used in the studies were of analytical grade. The concentrations of metal chloride solutions were determined by complexometric titration. The $\mathrm{GdCl}_{3}$ solution was prepared by dissolving $\mathrm{Gd}_{2} \mathrm{O}_{3}$ (Fluka, 99.9\%) in $6.0 \mathrm{M}$ $\mathrm{HCl}$, and the excess acid was evaporated off. The concentration of transition- and alkaline-earth-metal chloride solutions were determined by complexometric titration with the use of standardized $\mathrm{Na}_{2} \mathrm{H}_{2} \mathrm{EDTA}$ and xylenol orange $\left(\mathrm{GdCl}_{3}, \mathrm{ZnCl}_{2}\right)$, murexid $\left(\mathrm{CuCl}_{2}\right)$, Patton \& Reeder $\left(\mathrm{CaCl}_{2}\right)$, and eriochrome black $\mathrm{T}\left(\mathrm{MgCl}_{2}\right)$ as indicators.

The $\mathrm{pH}$-potentiometric titrations were carried out with a Metrohm $827 \mathrm{pH}$ Lab titration workstation using a Metrohm 6.0234.100 combined electrode. The solutions $(6.00 \mathrm{~mL})$ were thermostated at 25 ${ }^{\circ} \mathrm{C}$, stirred, and kept under an inert atmosphere $\left(\mathrm{N}_{2}\right)$ to avoid the effect of $\mathrm{CO}_{2}$. KH-phthalate ( $\left.\mathrm{pH} 4.005\right)$ and borax ( $\mathrm{pH}$ 9.177) buffers were used for the calibration of the electrodes. The concentration of the ligand solutions were determined by $\mathrm{pH}$-potentiometric titration. The protonation constants of the ligands and the stability and protonation constants of the metal complexes formed with $\mathrm{Ca}^{2+}, \mathrm{Mg}^{2+}$, and $\mathrm{Zn}^{2+}$ as well as the protonation constants of the $\mathrm{Cu}^{2+}$ complexes were also determined by $\mathrm{pH}$-potentiometric titration. The metal to ligand concentration ratios were 1:1 and 2:1, and the concentrations of the ligands were in the range of $2-4 \mathrm{mM}$ for $\mathbf{L}^{1}$ and $\mathrm{L}^{2}$ and $1.5-2 \mathrm{mM}$ for $\mathbf{L}^{3}$ and $\mathbf{L}^{4}$. During the titration $200-300 \mathrm{~mL}$ : $\mathrm{pH}$ data pairs were recorded between $\mathrm{pH} 1.7$ and 12 . For the calculation of $\left[\mathrm{H}^{+}\right]$from the $\mathrm{pH}$ values, the Irving method was used by titrating a $0.01 \mathrm{M} \mathrm{HCl}$ solution $(I=0.15 \mathrm{M} \mathrm{NaCl})$ with a standardized $\mathrm{NaOH}$ solution. ${ }^{59}$ The ion product of water was determined from the same experiment $(\mathrm{pH}$ 11.5-12). The protonation and the stability constants were calculated with the PSEQUAD program. ${ }^{60}$

The determination of the stability constants of $\mathrm{Cu}^{2+}$ complexes was carried out by means of the UV-vis spectrophotometric method, because of the high conditional stability of the $[\mathrm{Cu}(\mathrm{L})]$ complexes. For this reason, 9-12 samples were prepared containing $2 \mathrm{mM}$ of $\left[\mathrm{Cu}\left(\mathrm{L}^{1-4}\right)\right]$ and various concentrations of acid in the range of $0.05-$ 1.0 M. The stability constant and the molar absorptivity of the complexes were determined in the wavelength range of $570-770 \mathrm{~nm}$. The protonation and stability constants of $\mathrm{Cu}^{2+}$ complexes were determined by simultaneous fitting of $\mathrm{pH}$-potentiometric (obtained at $1: 1$ and 2:1 metal-to-ligand ratio) and UV-vis spectrophotometric data (obtained at 1:1 and 2:1 metal to ligand ratios (direct titrations) including out-of-cell samples prepared by using equimolar amounts of $\mathrm{Cu}^{2+}$ and $\mathrm{L}^{1-4}$ ). The constants were calculated with the PSEQUAD program.

The stability constants of the $\mathrm{Gd}^{3+}$ complexes were determined by measuring the longitudinal relaxation times (inversion recovery technique) using a Bruker Minispec MQ20 NMR analyzer (20 $\mathrm{MHz}, 25{ }^{\circ} \mathrm{C}$ ). A total of $20-25$ samples were prepared in the $\mathrm{pH}$ range $3-10$, where the concentrations of the complexes were $1.65 \mathrm{mM}$ for $\mathbf{L}^{1}$ and $\mathbf{L}^{2}$ and $1 \mathrm{mM}$ for $\mathbf{L}^{3}$ and $\mathbf{L}^{4}$ in the presence of $0.15 \mathrm{M} \mathrm{NaCl}$ as well as NMP ( $N$-methylpiperazine) and DMP (dimethylpiperazine) buffers. Because of the slow formation of the $\mathrm{Gd}^{3+}$ complexes, the $\left[\mathrm{Gd}\left(\mathrm{L}^{1-4}\right)\right]$ complexes were prepared as follows: the $\mathrm{pH}$ of the ligand solutions was set to 8.5 followed by the addition of the exact amount of the $\mathrm{Gd}^{3+}$ while vigorous stirring was used. After the formation of the complexes the $\mathrm{pH}$ was adjusted to 6 . This complex solution was used to prepare the samples. Over a period of a few days, when equilibrium was reached, the values of the relaxivity were recorded. The stability constants were calculated using the relaxivity of the $\mathrm{Gd}^{3+}$ aqua ion and the protonation constants of the ligands and the $\mathrm{Gd}^{3+}$ complexes.

Kinetic Measurements. The metal exchange reactions of the $\left[\mathrm{GdH}\left(\mathrm{L}^{1-4}\right)\right]$ complexes were determined by UV-vis spectrophotometry following the formation of the $\left[\mathrm{Cu}\left(\mathrm{L}^{1-4}\right)\right]$ complexes. The reactions were followed at $300 \mathrm{~nm}$ in the $\mathrm{pH}$ range 3.6-5.3. The concentrations of the complexes were $0.25 \mathrm{mM}$ for $\mathrm{GdL}^{1,2}$ and 0.1 $\mathrm{mM}$ for $\mathrm{GdL}^{3,4}$, while for $\mathrm{Cu}^{2+}$ ion concentration a $10-40$-fold excess was used to ensure pseudo-first-order conditions. The temperature was maintained at $25^{\circ} \mathrm{C}$, and the ionic strength was $0.15 \mathrm{M} \mathrm{NaCl}$. To keep the $\mathrm{pH}$ constant, NMP and DMP buffers were used at $30 \mathrm{mM}$ concentration. The pseudo-first-order rate constants $\left(k_{\mathrm{d}}\right)$ were calculated by fitting the data (absorbance versus time) to the equation

$$
A_{t}=\left(A_{0}-A_{\mathrm{e}}\right) \mathrm{e}^{-k_{\mathrm{d}} t}+A_{\mathrm{e}}
$$

where $A_{t}, A_{0}$, and $A_{\mathrm{e}}$ are the absorbances at time $t$, at the start and at the equilibrium of the reactions. The fittings were carried out with the computer program Micromath Scientist using a standard least-squares procedure. 
Relaxometric Experiments. The complexes $\mathrm{GdL}^{1-4}$ were dissolved in water, the concentration of stock solutions was determined using the bulk magnetic susceptibility method, ${ }^{61}$ and a series of buffered $\mathrm{GdL}^{1-4}$ solutions ranging from 3.0 to $5.0 \mathrm{mM}$ were prepared at $\mathrm{pH} 7.4$ in HEPES $(50 \mathrm{mM})$. The solutions were transferred into a $5 \mathrm{~mm}$ NMR tube equipped with a coaxial insert tube filled with $\mathrm{D}_{2} \mathrm{O}$ to lock the frequency. The longitudinal relaxation times were determined using the standard inversion recovery experiment on a $300 \mathrm{MHz}(7 \mathrm{~T})$ Bruker Avance III NMR spectrometer. The obtained relaxation times were converted into relaxation rates and plotted as a function of $\mathrm{Gd}^{3+}$ concentration in $\mathrm{mM}$. The longitudinal relaxivities of $\mathbf{G d L}^{1-4}\left(r_{1}\right.$ values $)$ were determined from the slope of the fitted line defined by eq 10 , where $R_{1, \mathrm{obs}}$ is the determined longitudinal relaxation rate, $R_{1, \mathrm{~d}}$ is the diamagnetic longitudinal relaxation rate $\left(R_{1}\right.$ in the absence of complex), and $\left[\mathrm{Gd}^{3+}\right]$ is the concentration of $\mathrm{Gd}^{3+}$ (equal to concentration of complex) used in the experiment.

$$
R_{1, \text { obs }}=R_{1, \mathrm{~d}}+r_{1}\left[\mathrm{Gd}^{3+}\right]
$$

Computational Details. Full geometry optimizations of the $\mathbf{E u L}^{n}$ complexes $(n=1-4)$ were using the hybrid meta-GGA TPSSh exchange-correlation functional ${ }^{62}$ and the Gaussian 09 package (Revision B.01). ${ }^{63}$ The large-core relativistic effective core potentials (LCRECP) of Dolg et al. ${ }^{.4}$ and the related [5s4p3d]-GTO valence basis sets were used for Eu. This ECP includes 52 electrons in the core for $\mathrm{Eu}^{3+}$. Since the six $4 \mathrm{f}$ electrons are included in the core, calculations were performed in a pseudo-singlet-state configuration. The ligand $\mathrm{C}$, $\mathrm{H}, \mathrm{N}$, and $\mathrm{O}$ atoms were described with the standard $6-31 \mathrm{G}(\mathrm{d}, \mathrm{p})$ basis. The stationary points found on the potential energy surfaces as a result of the geometry optimizations were confirmed to correspond to energy minima rather than saddle points using frequency analysis. Solvent effects (water) were evaluated by using the integral equation formalism variant of the polarizable continuum model (IEFPCM), ${ }^{65}$ as implemented in Gaussian 09.

\section{ASSOCIATED CONTENT}

\section{S Supporting Information}

The Supporting Information is available free of charge on the ACS Publications website at DOI: 10.1021/acs.inorgchem.8b00473.

Detailed synthetic procedures, speciation diagrams, UVvis spectra as a function of $\mathrm{pH}$ and $\left[\mathrm{H}^{+}\right]$obtained for $\mathrm{CuL}^{1-4}$ systems, ${ }^{1} \mathrm{H}$ NMR spectrum of $\mathrm{YbL}^{4}$, DFT calculated structures, kinetic data for $\mathbf{G d L}^{1}$ and $\mathbf{G d L}^{4}$, and optimized Cartesian coordinates obtained with DFT calculations (PDF)

\section{AUTHOR INFORMATION}

\section{Corresponding Authors}

*E-mail for F.K.K.: kalman.ferenc@science.unideb.hu.

*E-mail for G.A.: goran.angelovski@tuebingen.mpg.de.

\section{ORCID $\odot$}

David Esteban-Gómez: 0000-0001-6270-1660

Goran Angelovski: 0000-0002-8883-2631

\section{Notes}

The authors declare no competing financial interest.

\section{ACKNOWLEDGMENTS}

The authors acknowledge financial support from the Max Planck Society, Ministerio de Economía y Competitivad (CTQ2015-71211-REDT and CTQ2013-43243-P, support to C P.-I. and D.E.-G.), and Centro de Supercomputación de Galicia (CESGA) for providing the computer facilities. The research was supported in a part by the EU and cofinanced by the European Regional Development Fund under the projects GINOP-2.3.2-15-2016-00008 and GINOP-2.3.3-15-201600004. The technical assistance of Judit Bodnár and Anett Takács in some kinetic measurements is greatly appreciated. This work was partially done within the frame of the COST CA15209 Action "European Network on NMR Relaxometry".

\section{ABBREVIATIONS}

$\mathrm{CA}=$ contrast agent

$\mathrm{DFT}=$ density functional theory

DO3A $=1,4,7,10$-tetraazacyclododecane-1,4,7-triacetic acid

DOTA $=1,4,7,10$-tetraazacyclododecane-1,4,7,10-tetraacetic acid

DMAE-DO3A $=N, N$-dimethylaminoethyl-DO3A

DMP $=N, N^{\prime}$-dimethylpiperazine

DTPA = diethylenetriamine- $N, N, N^{\prime}, N^{\prime \prime}, N^{\prime \prime}$-pentaacetic acid

EAEA-DO3A = ethyleneamineethylamide-DO3A

EAPA-DO3A = ethyleneaminepropylamide-DO3A

EDTA $=$ ethylenediaminetetraacetate

EGTA = ethylene glycol-bis (2-aminoethyl ether)- $N, N, N^{\prime}, N^{\prime}$ tetraacetic acid

HEPES = 4-(2-hydroxyethyl)-1-piperazineethanesulfonic acid

IDA = iminodiacetate

MRI = magnetic resonance imaging

$\mathrm{NMP}=\mathrm{N}$-methylpiperazine

SAP $=$ square antiprismatic

SCAs $=$ bioresponsive or smart CAs

TACN $=1,4,7$-triazacyclononane

TSAP $=$ twisted square antiprismatic

\section{REFERENCES}

(1) Merbach, A. E.; Helm, L.; Tóth, É. The chemistry of contrast agents in medical magnetic resonance imaging, 2nd ed.; Wiley: Chichester, U.K., 2013.

(2) Heffern, M. C.; Matosziuk, L. M.; Meade, T. J. Lanthanide Probes for Bioresponsive Imaging. Chem. Rev. 2014, 114 (8), 4496-4539.

(3) Hingorani, D. V.; Bernstein, A. S.; Pagel, M. D. A review of responsive MRI contrast agents: 2005-2014. Contrast Media Mol. Imaging 2015, 10 (4), 245-265.

(4) Angelovski, G. Heading toward Macromolecular and Nanosized Bioresponsive MRI Probes for Successful Functional Imaging. Acc. Chem. Res. 2017, 50 (9), 2215-2224.

(5) Mamedov, I.; Mishra, A.; Angelovski, G.; Mayer, H. A.; Palsson, L. O.; Parker, D.; Logothetis, N. K. Synthesis and characterization of lanthanide complexes of DO3A-alkylphosphonates. Dalton Trans. 2007, 5260-5267.

(6) Angelovski, G.; Fouskova, P.; Mamedov, I.; Canals, S.; Toth, E.; Logothetis, N. K. Smart magnetic resonance imaging agents that sense extracellular calcium fluctuations. ChemBioChem 2008, 9 (11), 17291734.

(7) Dhingra, K.; Maier, M. E.; Beyerlein, M.; Angelovski, G.; Logothetis, N. K. Synthesis and characterization of a smart contrast agent sensitive to calcium. Chem. Commun. 2008, 29, 3444-3446.

(8) Regueiro-Figueroa, M.; Gündüz, S.; Patinec, V.; Logothetis, N. K.; Esteban-Gómez, D.; Tripier, R.; Angelovski, G.; Platas-Iglesias, C. $\mathrm{Gd}^{3+}$-Based Magnetic Resonance Imaging Contrast Agent Responsive to $\mathrm{Zn}^{2+}$. Inorg. Chem. 2015, 54 (21), 10342-10350.

(9) Oukhatar, F.; Meudal, H.; Landon, C.; Logothetis, N. K.; PlatasIglesias, C.; Angelovski, G.; Tóth, É. Macrocyclic Gd ${ }^{3+}$ Complexes with Pendant Crown Ethers Designed for Binding Zwitterionic Neurotransmitters. Chem. - Eur. J. 2015, 21 (31), 11226-11237.

(10) Oukhatar, F.; Même, S.; Même, W.; Szeremeta, F.; Logothetis, N. K.; Angelovski, G.; Tóth, É. MRI Sensing of Neurotransmitters with a Crown Ether Appended $\mathrm{Gd}^{3+}$ Complex. ACS Chem. Neurosci. 2015, 6 (2), 219-225. 
(11) Vibhute, S. M.; Engelmann, J.; Verbić, T.; Maier, M. E.; Logothetis, N. K.; Angelovski, G. Synthesis and characterization of $\mathrm{pH}-$ sensitive, biotinylated MRI contrast agents and their conjugates with avidin. Org. Biomol. Chem. 2013, 11 (8), 1294-1305.

(12) Angelovski, G.; Gottschalk, S.; Milošević, M.; Engelmann, J.; Hagberg, G. E.; Kadjane, P.; Andjus, P.; Logothetis, N. K. Investigation of a Calcium-Responsive Contrast Agent in Cellular Model Systems: Feasibility for Use as a Smart Molecular Probe in Functional MRI. ACS Chem. Neurosci. 2014, 5 (5), 360-369.

(13) Gündüz, S.; Nitta, N.; Vibhute, S.; Shibata, S.; Maier, M. E.; Logothetis, N. K.; Aoki, I.; Angelovski, G. Dendrimeric calciumresponsive MRI contrast agents with slow in vivo diffusion. Chem. Commun. 2015, 51 (14), 2782-2785.

(14) Moussaron, A.; Vibhute, S.; Bianchi, A.; Gündüz, S.; Kotb, S.; Sancey, L.; Motto-Ros, V.; Rizzitelli, S.; Crémillieux, Y.; Lux, F.; Logothetis, N. K.; Tillement, O.; Angelovski, G. Ultrasmall Nanoplatforms as Calcium-Responsive Contrast Agents for Magnetic Resonance Imaging. Small 2015, 11 (37), 4900-4909.

(15) Kadjane, P.; Platas-Iglesias, C.; Boehm-Sturm, P.; Truffault, V.; Hagberg, G. E.; Hoehn, M.; Logothetis, N. K.; Angelovski, G. DualFrequency Calcium-Responsive MRI Agents. Chem. - Eur. J. 2014, 20 (24), 7351-7362.

(16) Takacs, A.; Napolitano, R.; Purgel, M.; Benyei, A. C.; Zekany, L.; Brucher, E.; Toth, I.; Baranyai, Z.; Aime, S. Solution Structures, Stabilities, Kinetics, and Dynamics of DO3A and DO3A-Sulphonamide Complexes. Inorg. Chem. 2014, 53 (6), 2858-2872.

(17) Tei, L.; Baranyai, Z.; Gaino, L.; Forgacs, A.; Vagner, A.; Botta, M. Thermodynamic stability, kinetic inertness and relaxometric properties of monoamide derivatives of lanthanide(III) DOTA complexes. Dalton Trans. 2015, 44 (12), 5467-5478.

(18) Baranyai, Z.; Rolla, G. A.; Negri, R.; Forgacs, A.; Giovenzana, G. B.; Tei, L. Comprehensive Evaluation of the Physicochemical Properties of $\mathrm{Ln}^{\mathrm{III}}$ Complexes of Aminoethyl-DO3A as $\mathrm{pH}$-Responsive $T_{1}$-MRI Contrast Agents. Chem. - Eur. J. 2014, 20 (10), 2933-2944.

(19) Desreux, J. F.; Merciny, E.; Loncin, M. F. Nuclear MagneticResonance and Potentiometric Studies of the Protonation Scheme of 2 Tetraaza Tetraacetic Macrocycles. Inorg. Chem. 1981, 20 (4), 987991.

(20) Toth, E.; Kiraly, R.; Platzek, J.; Raduchel, B.; Brucher, E. Equilibrium and kinetic studies on complexes of 10-[2,3-dihydroxy-(1hydroxymethyl)-propyl]-1,4,7,10-tetraazacyclododecane-1,4,7-triacetate. Inorg. Chim. Acta 1996, 249 (2), 191-199.

(21) Huskens, J.; Torres, D. A.; Kovacs, Z.; Andre, J. P.; Geraldes, C. F. G. C.; Sherry, A. D. Alkaline earth metal and lanthanide(III) complexes of ligands based upon 1,4,7,10-tetraazacyclododecane-1,7bis(acetic acid). Inorg. Chem. 1997, 36 (7), 1495-1503.

(22) Le Fur, M.; Molnar, E.; Beyler, M.; Kalman, F. K.; Fougere, O.; Esteban-Gomez, D.; Rousseaux, O.; Tripier, R.; Tircso, G.; PlatasIglesias, C. A Coordination Chemistry Approach to Fine-Tune the Physicochemical Parameters of Lanthanide Complexes Relevant to Medical Applications. Chem. - Eur. J. 2018, 24 (13), 3127-3131.

(23) Anderegg, G.; Arnaud-Neu, F.; Delgado, R.; Felcman, J.; Popov, K. Critical Evaluation of Stability Constants of Metal Complexes for Biomedical and Environmental Applications (IUPAC Technical Report). Pure Appl. Chem. 2005, 77 (8), 1445-1495.

(24) Jancso, A.; Selmeczi, K.; Gizzi, P.; Nagy, N. V.; Gajda, T.; Henry, B. The role of terminal amino group and histidine at the fourth position in the metal ion binding of oligopeptides revisited Copper(II) and nickel(II) complexes of glycyl-glycyl-glycyl-histamine and its $\mathrm{N}$ Boc protected derivative. J. Inorg. Biochem. 2011, 105 (1), 92-101.

(25) Toth, E.; Brucher, E.; Lazar, I.; Toth, I. Kinetics of Formation and Dissociation of Lanthanide(III)-DOTA Complexes. Inorg. Chem. 1994, 33 (18), 4070-4076.

(26) Kumar, K.; Tweedle, M. F. Ligand Basicity and Rigidity Control Formation of Macrocyclic Polyamino Carboxylate Complexes of Gadolinium(III). Inorg. Chem. 1993, 32 (20), 4193-4199.

(27) Rojas-Quijano, F. A.; Tircso, G.; Benyo, E. T.; Baranyai, Z.; Hoang, H. T.; Kalman, F. K.; Gulaka, P. K.; Kodibagkar, V. D.; Aime, S.; Kovacs, Z.; Sherry, A. D. Synthesis and Characterization of a
Hypoxia-Sensitive MRI Probe. Chem. - Eur. J. 2012, 18 (31), 96699676.

(28) Balogh, E.; Tripier, R.; Fouskova, P.; Reviriego, F.; Handel, H.; Toth, E. Monopropionate analogues of $\mathrm{DOTA}^{4-}$ and $\mathrm{DTPA}^{5-}$ : kinetics of formation and dissociation of their lanthanide(III) complexes. Dalton Trans. 2007, 32, 3572-3581.

(29) Platas, C.; Avecilla, F.; de Blas, A.; Rodriguez-Blas, T.; Geraldes, C. F. G. C.; Toth, E.; Merbach, A. E.; Bunzli, J. C. G. Mono- and bimetallic lanthanide(III) phenolic cryptates obtained by template reaction: solid state structure, photophysical properties and relaxivity. J. Chem. Soc., Dalton Trans. 2000, 4, 611-618.

(30) Lowe, M. P.; Parker, D.; Reany, O.; Aime, S.; Botta, M.; Castellano, G.; Gianolio, E.; Pagliarin, R. pH-dependent modulation of relaxivity and luminescence in macrocyclic gadolinium and europium complexes based on reversible intramolecular sulfonamide ligation. J. Am. Chem. Soc. 2001, 123 (31), 7601-7609.

(31) Aime, S.; Botta, M.; Fasano, M.; Marques, M. P. M.; Geraldes, C. F. G. C.; Pubanz, D.; Merbach, A. E. Conformational and Coordination Equilibria on DOTA Complexes of Lanthanide Metal Ions in Aqueous Solution Studied by ${ }^{1} \mathrm{H}-\mathrm{NMR}$ Spectroscopy. Inorg. Chem. 1997, 36 (10), 2059-2068.

(32) Parker, D.; Dickins, R. S.; Puschmann, H.; Crossland, C.; Howard, J. A. K. Being excited by lanthanide coordination complexes: Aqua species, chirality, excited-state chemistry, and exchange dynamics. Chem. Rev. 2002, 102 (6), 1977-2010.

(33) Adair, C.; Woods, M.; Zhao, P. Y.; Pasha, A.; Winters, P. M.; Lanza, G. M.; Athey, P.; Sherry, A. D.; Kiefer, G. E. Spectral properties of a bifunctional PARACEST europium chelate: an intermediate for targeted imaging applications. Contrast Media Mol. Imaging 2007, 2 (1), 55-58.

(34) Regueiro-Figueroa, M.; Djanashvili, K.; Esteban-Gomez, D.; Chauvin, T.; Toth, E.; de Blas, A.; Rodriguez-Blas, T.; Platas-Igleslas, C. Molecular Recognition of Sialic Acid by Lanthanide(III) Complexes through Cooperative Two-Site Binding. Inorg. Chem. 2010, 49 (9), 4212-4223.

(35) Polasek, M.; Kotek, J.; Hermann, P.; Cisarova, I.; Binnemans, K.; Lukes, I. Lanthanide(III) Complexes of Pyridine-N-Oxide Analogues of DOTA in Solution and in the Solid State. A Near Kind of Isomerism in Complexes of DOTA-like Ligands. Inorg. Chem. 2009, 48 (2), 466-475.

(36) Dunand, F. A.; Dickins, R. S.; Parker, D.; Merbach, A. E. Towards Rational Design of Fast Water-Exchanging Gd(dota-like) Contrast Agents? Importance of the $\mathrm{M} / \mathrm{m}$ Ratio. Chem. - Eur. J. 2001, 7 (23), 5160-5167.

(37) Aime, S.; Botta, M.; Ermondi, G. NMR Study of Solution Structures and Dynamics of Lanthanide(III) Complexes of DOTA. Inorg. Chem. 1992, 31 (21), 4291-4299.

(38) Caravan, P.; Ellison, J. J.; McMurry, T. J.; Lauffer, R. B. Gadolinium(III) chelates as MRI contrast agents: Structure, dynamics, and applications. Chem. Rev. 1999, 99 (9), 2293-2352.

(39) Natrajan, L. S.; Villaraza, A. J. L.; Kenwright, A. M.; Faulkner, S. Controlled preparation of a heterometallic lanthanide complex containing different lanthanides in symmetrical binding pockets. Chem. Commun. 2009, 40, 6020-6022.

(40) Main, M.; Snaith, J. S.; Meloni, M. M.; Jauregui, M.; Sykes, D.; Faulkner, S.; Kenwright, A. M. Using the Ugi multicomponent condensation reaction to prepare families of chromophore appended azamacrocycles and their complexes. Chem. Commun. 2008, 41, 52125214.

(41) Nonat, A.; Regueiro-Figueroa, M.; Esteban-Gomez, D.; de Blas, A.; Rodriguez-Blas, T.; Platas-Iglesias, C.; Charbonniere, L. J. Definition of an Intramolecular Eu-to-Eu Energy Transfer within a Discrete $\left[\mathrm{Eu}_{2} \mathrm{~L}\right]$ Complex in Solution. Chem. - Eur. J. 2012, 18 (26), $8163-8173$.

(42) Purgel, M.; Baranyai, Z.; de Blas, A.; Rodriguez-Blas, T.; Banyai, I.; Platas-Iglesias, C.; Toth, I. An NMR and DFT Investigation on the Conformational Properties of Lanthanide(III) 1,4,7,10-Tetraazacyclododecane-1,4,7,10-tetraacetate Analogues Containing Methylenephosphonate Pendant Arms. Inorg. Chem. 2010, 49 (9), 4370-4382. 
(43) Binnemans, K. Interpretation of europium(III) spectra. Coord. Chem. Rev. 2015, 295, 1-45.

(44) Dickins, R. S.; Parker, D.; Bruce, J. I.; Tozer, D. J. Correlation of optical and NMR spectral information with coordination variation for axially symmetric macrocyclic $\mathrm{Eu}(\mathrm{III})$ and $\mathrm{Yb}(\mathrm{III})$ complexes: axial donor polarisability determines ligand field and cation donor preference. Dalton Trans. 2003, No. 7, 1264-1271.

(45) Beeby, A.; Clarkson, I. M.; Dickins, R. S.; Faulkner, S.; Parker, D.; Royle, L.; de Sousa, A. S.; Williams, J. A. G.; Woods, M. Nonradiative deactivation of the excited states of europium, terbium and ytterbium complexes by proximate energy-matched $\mathrm{OH}, \mathrm{NH}$ and $\mathrm{CH}$ oscillators: an improved luminescence method for establishing solution hydration states. J. Chem. Soc., Perkin Trans. 2 1999, No. 3, 493-503.

(46) Supkowski, R. M.; Horrocks, W. D. On the determination of the number of water molecules, $q$, coordinated to europium(III) ions in solution from luminescence decay lifetimes. Inorg. Chim. Acta 2002, 340, 44-48.

(47) Rodriguez-Rodriguez, A.; Regueiro-Figueroa, M.; EstebanGomez, D.; Rodriguez-Blas, T.; Patinec, V.; Tripier, R.; Tircso, G.; Carniato, F.; Botta, M.; Platas-Iglesias, C. Definition of the Labile Capping Bond Effect in Lanthanide Complexes. Chem. - Eur. J. 2017, 23 (5), 1110-1117.

(48) Sherry, A. D.; Caravan, P.; Lenkinski, R. E. Primer on Gadolinium Chemistry. J. Magn. Reson. Imaging 2009, 30 (6), 12401248.

(49) Angelovski, G.; Mamedov, I. Cation-Responsive MRI Contrast Agents Based on Gadolinium(III). Curr. Inorg. Chem. 2011, 1 (1), 7690.

(50) Polasek, M.; Caravan, P. Is Macrocycle a Synonym for Kinetic Inertness in $\mathrm{Gd}(\mathrm{III})$ Complexes? Effect of Coordinating and Noncoordinating Substituents on Inertness and Relaxivity of Gd(III) Chelates with DO3A-like Ligands. Inorg. Chem. 2013, 52 (7), 40844096

(51) Baranyai, Z.; Palinkas, Z.; Uggeri, F.; Maiocchi, A.; Aime, S.; Brucher, E. Dissociation Kinetics of Open-Chain and Macrocyclic Gadolinium(III)-Aminopolycarboxylate Complexes Related to Magnetic Resonance Imaging: Catalytic Effect of Endogenous Ligands. Chem. - Eur. J. 2012, 18 (51), 16426-16435.

(52) Sarka, L.; Burai, L.; Kiraly, R.; Zekany, L.; Brucher, E. Studies on the kinetic stabilities of the $\mathrm{Gd}^{3+}$ complexes formed with the $\mathrm{N}$ mono(methylamide), $N^{\prime}$-mono(methylamide) and $N, N^{\prime \prime}$-bis(methylamide) derivatives of diethylenetriamine- $N, N, N^{\prime}, N^{\prime \prime}, N^{\prime \prime}$-pentaacetic acid. J. Inorg. Biochem. 2002, 91 (1), 320-326.

(53) Baranyai, Z.; Brucher, E.; Ivanyi, T.; Kiraly, R.; Lazar, I.; Zekany, L. Complexation Properties of $N, N^{\prime}, N^{\prime \prime}, N^{\prime \prime \prime}$-[1,4,7,10-Tetraazacyclododecane-1,4,7,10-tetrayltetrakis(1-oxoethane-2,1-diyl)] tetrakis[glycine] $\left(\mathrm{H}_{4}\right.$ dotagl). Equilibrium, Kinetic, and Relaxation Behavior of the Lanthanide(III) Complexes. Helv. Chim. Acta 2005, 88 (3), 604617.

(54) Regueiro-Figueroa, M.; Bensenane, B.; Ruscsak, E.; EstebanGomez, D.; Charbonniere, L. J.; Tircso, G.; Toth, I.; de Blas, A.; Rodriguez-Blas, T.; Platas-Iglesias, C. Lanthanide dota-like Complexes Containing a Picolinate Pendant: Structural Entry for the Design of Ln(III)-Based Luminescent Probes. Inorg. Chem. 2011, 50 (9), 41254141

(55) Taborsky, P.; Lubal, P.; Havel, J.; Kotek, J.; Hermann, P.; Lukes, I. Thermodynamic and Kinetic Studies of Lanthanide(III) Complexes with $\mathrm{H}_{5}$ do3ap $(1,4,7,10$-Tetraazacyclododecane-1,4,7-triacetic-10(methylphosphonic Acid)), a Monophosphonate Analogue of $\mathrm{H}_{4}$ dota. Collect. Czech. Chem. Commun. 2005, 70 (11), 1909-1942.

(56) Taborsky, P.; Svobodova, I.; Lubal, P.; Hnatejko, Z.; Lis, S.; Hermann, P. Formation and dissociation kinetics of $\mathrm{Eu}(\mathrm{III})$ complexes with $\mathrm{H}_{5}$ do3ap and similar dota-like ligands. Polyhedron 2007, 26 (15), 4119-4130.

(57) Placidi, M. P.; Botta, M.; Kalman, F. K.; Hagberg, G. E.; Baranyai, Z.; Krenzer, A.; Rogerson, A. K.; Toth, I.; Logothetis, N. K.; Angelovski, G. Aryl-Phosphonate Lanthanide Complexes and Their Fluorinated Derivatives: Investigation of Their Unusual Relaxometric
Behavior and Potential Application as Dual Frequency ${ }^{1} \mathrm{H} /{ }^{19} \mathrm{~F}$ MRI Probes. Chem. - Eur. J. 2013, 19 (35), 11644-60.

(58) Aime, S.; Barge, A.; Botta, M.; Frullano, L.; Merlo, U.; Hardcastle, K. I. Multinuclear and multifrequency NMR study of gadolinium(III) complexes with bis-amide derivatives of ethylenedioxydiethylenedinitrilotetraacetic acid. J. Chem. Soc., Dalton Trans. 2000, 19, 3435-3440.

(59) Irving, H. M.; Miles, M. G.; Pettit, L. D. A Study of Some Problems in Determining Stoicheiometric Proton Dissociation Constants of Complexes by Potentiometric Titrations Using a Glass Electrode. Anal. Chim. Acta 1967, 38 (4), 475-488.

(60) Zekany, L.; Nagypal, I. In Computational Methods for the Determination of Formation Constants; Leggett, D. J., Ed.; Springer US: Boston, MA, 1985; pp 291-353.

(61) Corsi, D. M.; Platas-Iglesias, C.; van Bekkum, H.; Peters, J. A. Determination of paramagnetic lanthanide(III) concentrations from bulk magnetic susceptibility shifts in NMR spectra. Magn. Reson. Chem. 2001, 39 (11), 723-726.

(62) Tao, J. M.; Perdew, J. P.; Staroverov, V. N.; Scuseria, G. E. Climbing the density functional ladder: Nonempirical meta-generalized gradient approximation designed for molecules and solids. Phys. Rev. Lett. 2003, 91 (14), 146401.

(63) Frisch, M. J.; Trucks, G. W.; Schlegel, H. B.; Scuseria, G. E.; Robb, M. A.; Cheeseman, J. R.; Scalmani, G.; Barone, V.; Mennucci, B.; Petersson, G. A.; Nakatsuji, H.; Caricato, M.; Li, X.; Hratchian, H. P.; Izmaylov, A. F.; Bloino, J.; Zheng, G.; Sonnenberg, J. L.; Hada, M.; Ehara, M.; Toyota, K.; Fukuda, R.; Hasegawa, J.; Ishida, M.; Nakajima, T.; Honda, Y.; Kitao, O.; Nakai, H.; Vreven, T.; Montgomery, J. A.; Peralta, J. E.; Ogliaro, F.; Bearpark, M.; Heyd, J. J.; Brothers, E.; Kudin, K. N.; Staroverov, V. N.; Kobayashi, R.; Normand, J.; Raghavachari, K.; Rendell, A.; Burant, J. C.; Iyengar, S. S.; Tomasi, J.; Cossi, M.; Rega, N.; Millam, J. M.; Klene, M.; Knox, J. E.; Cross, J. B.; Bakken, V.; Adamo, C.; Jaramillo, J.; Gomperts, R.; Stratmann, R. E.; Yazyev, O.; Austin, A. J.; Cammi, R.; Pomelli, C.; Ochterski, J. W.; Martin, R. L.; Morokuma, K.; Zakrzewski, V. G.; Voth, G. A.; Salvador, P.; Dannenberg, J. J.; Dapprich, S.; Daniels, A. D.; Farkas; Foresman, J. B.; Ortiz, J. V.; Cioslowski, J.; Fox, D. J. Gaussian 09, Revision B.01; Gaussian, Inc.: Wallingford, CT, 2009.

(64) Dolg, M.; Stoll, H.; Savin, A.; Preuss, H. Energy-Adjusted Pseudopotentials for the Rare-Earth Elements. Theor. Chim. Acta 1989, 75 (3), 173-194.

(65) Tomasi, J.; Mennucci, B.; Cammi, R. Quantum mechanical continuum solvation models. Chem. Rev. 2005, 105 (8), 2999-3093. 